\title{
Outcomes Associated With Isolated Agenesis of the Corpus Callosum: A Meta-analysis
}

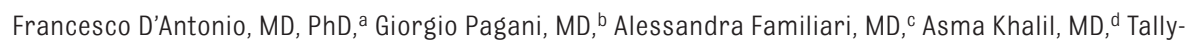
Lerman Sagies, MD, PhD, e,f Gustavo Malinger, MD,e, z Zvi Leibovitz, MD, e, h Catherine Garel, MD, PhD, 'Marie Laure Moutard, MD, PhD, Gianluigi Pilu, MD, PhD, ${ }^{\mathrm{k}}$ Amar Bhide, MD, ${ }^{d}$ Ganesh Acharya, MD, PhD, ${ }^{a}$ Martina Leombroni, MD,' Lamberto Manzoli, MD, PhD, ${ }^{\mathrm{m}, \mathrm{n}}$ Aris Papageorghiou, MD, ${ }^{\mathrm{d}}$ Federico Prefumo, MD, PhD ${ }^{\circ}$

CONTEXT: Antenatal counseling in cases of agenesis of the corpus callosum (ACC) is challenging.

OBJECTIVES: To ascertain the outcome in fetuses with isolated complete ACC and partial ACC.

DATA SOURCES: Medline, Embase, CINAHL, and Cochrane databases.

Study SELECtION: Studies reporting a prenatal diagnosis of ACC. The outcomes observed were: chromosomal abnormalities at standard karyotype and chromosomal microarray (CMA) analysis, additional anomalies detected only at prenatal MRI and at postnatal imaging or clinical evaluation, concordance between prenatal and postnatal diagnosis and neurodevelopmental outcome.

DATA EXTRACTION: Meta-analyses of proportions were used to combine data.

RESULTS: Twenty-seven studies were included. In cACC, chromosomal anomalies occurred in 4.81\% (95\% confidence interval [CI], 2.2-8.4) of the cases. Gross and fine motor control were abnormal in $4.40 \%$ (95\% CI, 0.6-11.3) and 10.98\% (95\% CI, 4.1-20.6) of the cases, respectively, whereas $6.80 \%$ (95\% CI, 1.7-14.9) presented with epilepsy. Abnormal cognitive status occurred in $15.16 \%$ (95\% CI, 6.9-25.9) of cases. In partial ACC, the rate of chromosomal anomalies was 7.45\% (95\% CI, 2.0-15.9). Fine motor control was affected in $11.74 \%$ (95\% CI, 0.9-32.1) of the cases, and $16.11 \%$ (95\% CI, 2.5-38.2) presented with epilepsy. Cognitive status was affected in $17.25 \%$ (95\% CI, 3.0-39.7) of cases.

LIMITATIONS: Different neurodevelopmental tools and time of follow-up of the included studies. conclusions: Children wih a prenatal diagnosis of isolated ACC show several degrees of impairment in motor control, coordination, language, and cognitive status. However, in view of the large heterogeneity in outcomes measures, time at follow-up, and neurodevelopmental tools used, large prospective studies are needed to ascertain the actual occurrence of neuropsychological morbidity of children with isolated ACC. 
Agenesis of the corpus callosum (ACC) is one of the most common congenital brain anomalies, with an estimated prevalence ranging from 1.8 per 10000 in the general population to 230-600 per 10000 in children with neurodevelopmental disabilities. $^{1-3}$

Neurodevelopmental outcome for individuals with callosal abnormalities is extremely variable even between children sharing similar neuroanatomic profiles, and there is often significant overlapping in the neuropsychological performance between patients with complete ACC (cACC) and those with partial ACC (pACC). ${ }^{4}$ Delay in motor and cognitive functions, epilepsy, and social and language deficits are the most common symptoms reported in individuals with ACC; furthermore, ACC has been linked with the occurrence of autism, schizophrenia, and attention-deficit disorders. ${ }^{5-9}$ However, pediatric series are biased by the fact that only symptomatic cases are reported.

Advances in prenatal imaging techniques have led to an increase the detection rate of ACC; however, antenatal counseling when a fetus is diagnosed with this anomaly is still challenging. ${ }^{5}$

Chromosomal abnormalities are common in ACC, especially when associated anomalies are present, and prenatal invasive tests are usually performed in pregnancy to rule out aneuploidies. Chromosomal microarray (CMA) allows the detection of small genomic deletions and duplications that are not routinely seen on standard cytogenetic analysis (copy number variations [CNVs]). Fetuses with central nervous system (CNS) anomalies and normal karyotype have been shown to have a significantly higher risk of genetic anomalies at CMA analysis; however, the risk of clinically significant CNVs in fetuses with isolated callosal anomalies has not been completely ascertained yet. ${ }^{10,11}$

Antenatal MRI is usually performed to rule out associated anomalies, which are major determinants of outcome in cases of ACC; however, the actual diagnostic accuracy of fetal MRI in isolated ACC is still debated. ${ }^{12}$

Neurodevelopmental outcome in fetuses with isolated ACC has been reported to be normal in a large majority of cases, especially in complete agenesis. However, a precise categorization of the burden of neuropsychological disabilities is required to counsel parents more appropriately. ${ }^{13}$

The first aim of this systematic review was to ascertain the rate of associated genetic or anatomic abnormalities in those patients with an initial ultrasound examination showing isolated ACC; the secondary aim was to explore the neurodevelopmental status of these children.

\section{METHODS}

\section{Protocol, Eligibility Criteria, Information Sources, and Search}

This review was performed according to an a priori designed protocol and recommended for systematic reviews and meta-analysis. ${ }^{14,15}$ Medline, Embase, CINAHL, and Cochrane databases were searched electronically on February 15, 2014 using combinations of the relevant medical subject heading terms, key words, and word variants for "agenesis of the corpus callosum" and "outcome"; the search was then updated on November 26, 2015 (Supplemental Table 5). The search and selection criteria were restricted to English. Reference lists of relevant articles and reviews were hand searched for additional reports. PRISMA guidelines were followed. ${ }^{16}$
Study Selection, Data Collection, and Data Items

Studies were assessed according to the following criteria: population, type of callosal agenesis (cACC and pACC) outcome, type of imaging assessment, and outcome (Table 1).

Two authors (F.D. and G.P.) reviewed all abstracts independently.

Agreement regarding potential relevance was reached by consensus; full-text copies of those papers were obtained and the same 2 reviewers independently extracted relevant data regarding study characteristics and pregnancy outcome.

Inconsistencies were discussed by the reviewers and consensus reached with a third author. If $>1$ study was published for the same cohort with identical end points, the report containing the most comprehensive information on the population was included to avoid overlapping populations. For those articles in which information was not reported but the methodology was such that this information would have been recorded initially, the authors were contacted.

Quality assessment of the included studies was performed using the Newcastle-Ottawa Scale (NOS) for cohort studies (Table 2). According to NOS, each study is judged on 3 broad perspectives: the selection of the study groups, the comparability of the groups, and the ascertainment outcome of interest. ${ }^{44}$ Assessment of the selection of a study includes the evaluation of the representativeness of the exposed cohort, selection of the nonexposed cohort, ascertainment of exposure, and the demonstrating that outcome of interest was not present at the start of the study. Assessment of the comparability of the study includes the evaluation of the comparability of cohorts on the basis of the design or analysis. Finally, the ascertainment of the outcome of interest includes the evaluation of the type of assessment of the outcome of interest, length, and adequacy of 


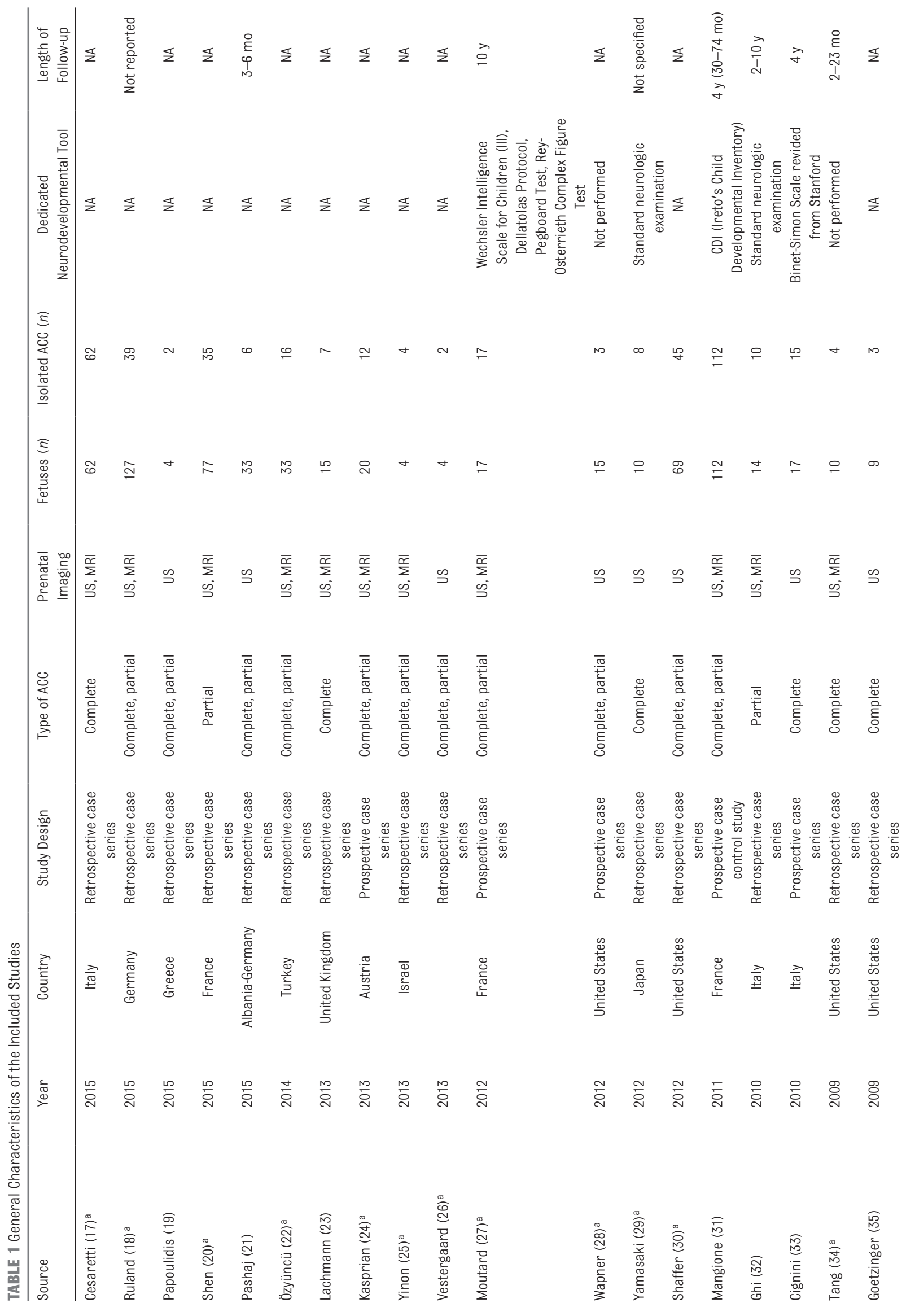




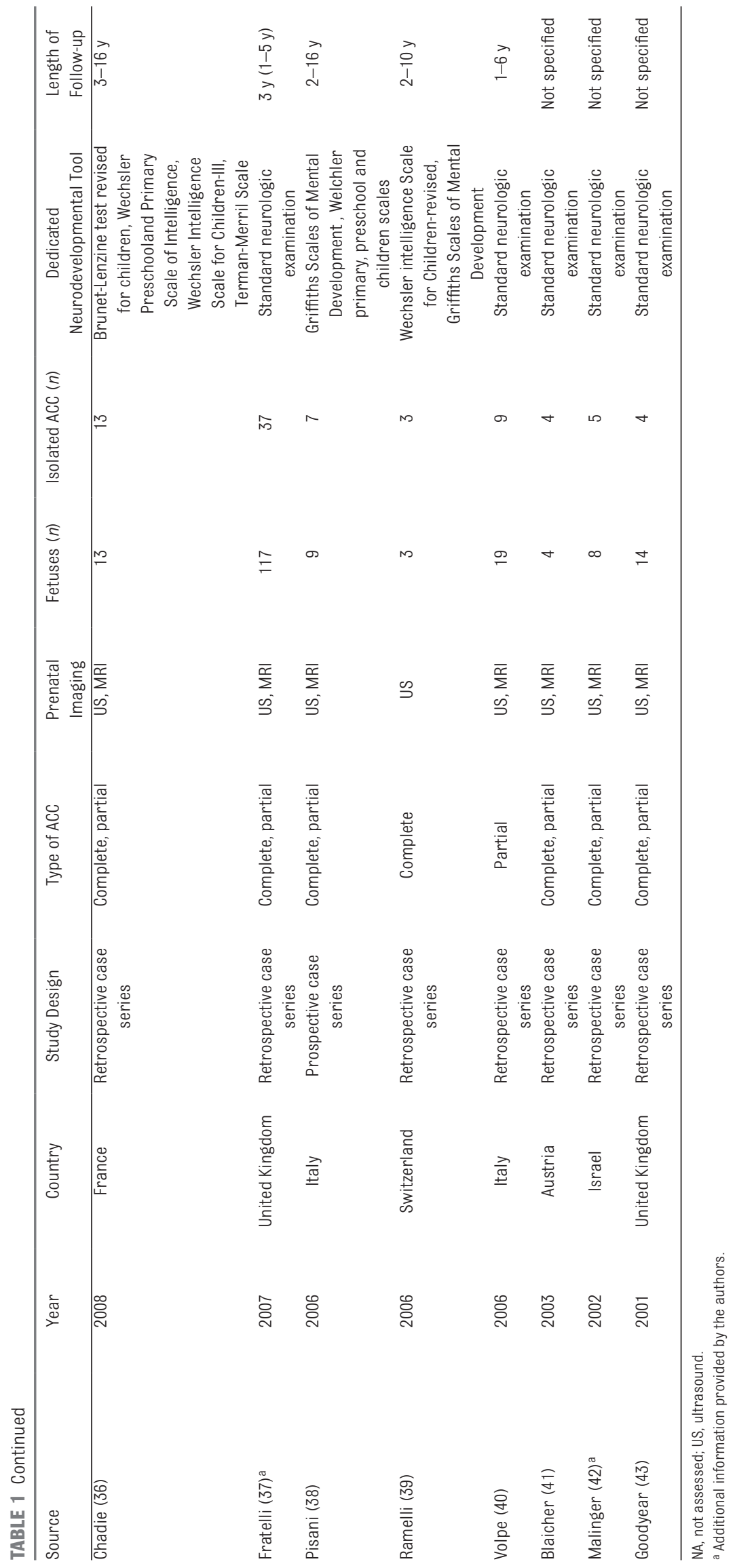

follow-up. According to NOS, a study can be awarded a maximum of 1 star for each numbered item within the Selection and Outcome categories. A maximum of 2 stars can be given for the Comparability category. ${ }^{44}$

\section{Risk of Bias, Summary Measures, and Synthesis of the Results}

The incidence of the following outcomes was analyzed in fetuses with a prenatal diagnosis of cACC and pACC separately:

1. Chromosomal abnormalities detected with standard karyotype analysis.

2. Pathogenic CNVs at CMA.

3. Rate of additional CNS anomalies detected only at prenatal MRI but missed at the initial scan.

4. Additional CNS and extra-CNS anomalies detected only at postnatal imaging or clinical evaluation but missed at prenatal imaging.

5. Concordance between prenatal and postnatal diagnosis.

6. Neurodevelopmental outcome.

Only fetuses with a prenatal diagnosis of ACC either by transabdominal or transvaginal ultrasound were included. cACC was defined as the total absence of all the anatomically defined regions of the corpus callosum, whereas pACC was defined as the presence of at least 1 region of the corpus callosum. For the assessment of the incidence of abnormal karyotype, only cases of isolated ACC defined as having no additional CNS and extra-CNS anomalies detected at the ultrasound scan were included in the analysis. Only cases who had their full karyotype tested either prenatally or postnatally were included. For the occurrence of genetic abnormalities detected only at CMA only fetuses with isolated ACC and normal standard karyotype were considered suitable for the analysis. The presence of additional 
anomalies detected only at prenatal and postnatal MRI were assessed only in fetuses with no additional anomalies and normal karyotype. For the purpose of this study, mild to moderate ventriculomegaly (defined as a lateral ventricle width $\leq 15 \mathrm{~mm}$ ) was not included as an associated cerebral malformation because its development is related to brain re-organization due to callosal agenesis.

The neurodevelopmental outcome of infants with ACC was ascertained exclusively in cases of isolated ACC with normal full standard karyotype and no other SNC and extra-CNS anomalies confirmed postnatally. Cases with isolated ACC confirmed at postnatal imaging but showing extracerebral anomalies at clinical examination were not included in the analysis. Furthermore, because the large majority of the studies showing the contribution of CMA in fetuses with isolated ACC did not report the neurodevelopmental outcome, it was not possible to perform a subanalysis to ascertain the neurologic profile of those cases with normal standard karyotype and no clinically significant CNVs found at CMA.

Neurodevelopmental outcome was divided into 3 different categories (normal, borderline/moderate, and severe) as defined by the original study. Furthermore, to provide a more objective estimation of the neurologic performance of these children, we also assessed the neurodevelopmental outcome in terms of: (1) gross motor control, (2) fine motor control, (3) cognitive status, (4) epilepsy, (5) visual control, (6) sensory status, (7) language, and (8) coordination. All of these figures were ascertained for fetuses with cACC and pACC separately.

Only studies reporting a prenatal diagnosis of ACC were considered suitable for inclusion in the current systematic review; postnatal studies or studies from which cases diagnosed prenatally could not be

TABLE 2 Quality Assessment of the Included Studies

\begin{tabular}{|c|c|c|c|c|}
\hline Author & Year & Selection & Comparability & Outcome \\
\hline Cesaretti (17) & 2015 & $\star \star \star$ & $\star \star$ & $\star \star$ \\
\hline Ruland (18) & 2015 & $\star \star$ & $\star$ & $\star$ \\
\hline Papoulidis (19) & 2015 & $\star \star \star$ & $\star \star$ & $\star \star \star$ \\
\hline Shen (20) & 2015 & $\star \star$ & $\star$ & $\star$ \\
\hline Pashaj (21) & 2014 & $\star \star$ & $\star$ & $\star \star$ \\
\hline Özyüncü (22) & 2014 & $\star \star$ & $\star$ & $\star \star$ \\
\hline Lachmann (23) & 2013 & $\star \star$ & $\star$ & $\star \star$ \\
\hline Kasprian (24) & 2013 & $\star \star$ & $\star$ & $\star$ \\
\hline Yinon (25) & 2013 & $\star \star$ & $\star$ & $\star \star$ \\
\hline Vestergaard (26) & 2012 & $\star \star \star$ & $\star \star$ & $\star \star \star$ \\
\hline Moutard (27) & 2012 & $\star \star$ & $\star$ & $\star$ \\
\hline Wapner (28) & 2011 & $\star \star \star \star$ & $\star \star \star$ & $\star \star \star \star$ \\
\hline Yamasaki (29) & 2010 & $\star \star \star$ & $\star \star$ & $\star \star \star$ \\
\hline Shaffer (30) & 2010 & $\star \star$ & $\star$ & $\star \star$ \\
\hline Mangione (31) & 2009 & $\star \star \star$ & $\star$ & $\star \star$ \\
\hline Ghi (32) & 2009 & $\star \star$ & $\star$ & $\star$ \\
\hline Cignini (33) & 2008 & $\star \star \star$ & $\star \star$ & $\star \star$ \\
\hline Tang (34) & 2007 & $\star \star$ & $\star$ & $\star \star$ \\
\hline Goetzinger (35) & 2006 & $\star \star \star$ & $\star$ & $\star \star$ \\
\hline Chadie (36) & 2006 & $\star \star$ & $\star$ & $\star \star$ \\
\hline Fratelli (37) & 2006 & $\star \star \star$ & $\star \star$ & $\star \star \star$ \\
\hline Pisani (38) & 2003 & $\star \star$ & $\star$ & $\star$ \\
\hline Ramelli (39) & 2002 & $\star \star \star$ & $\star \star$ & $\star \star \star \star$ \\
\hline Volpe (40) & 2001 & $\star$ & $\star$ & $\star$ \\
\hline Blaicher (41) & 2003 & $\star \star$ & $\star$ & $\star$ \\
\hline Malinger (42) & 2002 & $\star \star$ & $\star$ & $\star$ \\
\hline Goodyear (43) & 2001 & $\star$ & $\star$ & $\star \star$ \\
\hline
\end{tabular}

According to NOS a study can be awarded a maximum of one star for each numbered item within the Selection and Outcome categories. A maximum of two stars can be given for Comparability. ${ }^{44}$

extracted were excluded. Cases with dysgenesis and/or hypoplasia of the corpus callosum and those with lack of a clear definition of the anomaly were not considered suitable for inclusion. Autopsy-based studies were excluded on the basis that fetuses undergoing termination of pregnancy are more likely to show associated major structural and chromosomal anomalies. Studies reporting the concordance between prenatal and postnatal diagnosis of ACC were excluded unless they provided information about whether the anomaly was isolated or not. Studies of nonisolated cases of ACC were excluded as were studies published before 2000, because we felt that advances in prenatal imaging techniques and improvements in the diagnosis and definition of CNS anomalies make these studies less relevant. Finally, studies that did not provide a clear classification of the anomaly and those that did not differentiate between cACC and pACC were not considered suitable for inclusion in the current review. However, because it was not possible to extrapolate the figures for the occurrence of pathogenic CNVs in fetuses with cACC and pACC separately, this outcome was ascertained in the overall population of fetuses with callosal agenesis.

Only full-text articles were considered eligible for inclusion; case reports, conference abstracts, and case series with $<3$ cases of ACC, irrespective of whether the anomalies were isolated or not, were also excluded to avoid publication bias.

We used meta-analyses of proportions to combine data. ${ }^{45}$ Funnel plots (Supplemental Figs 10, $11,12,13$, and 14) displaying the outcome rate from individual studies versus their precision (1 per SE) were carried out with an exploratory aim. Tests for funnel plot asymmetry were not used when the 
total number of publications included for each outcome was $<10$. In this case, the power of the tests is too low to distinguish chance from real asymmetry. ${ }^{45,46}$

Between-study heterogeneity was explored using the $\mathrm{I}^{2}$ statistic, which represents the percentage of between-study variation that is due to heterogeneity rather than chance. A value of $0 \%$ indicates no observed heterogeneity, whereas $\mathrm{I}^{2}$ values $\geq 50 \%$ indicate a substantial level of heterogeneity. fixed effects model was used if substantial statistical heterogeneity was not present. In contrast, if there was evidence of significant heterogeneity between studies included, a random effect model was used. ${ }^{47}$

All proportion meta-analyses were carried out by using StatsDirect version 2.7.9 (StatsDirect, Ltd, Altrincham, Cheshire, United Kingdom).

\section{RESULTS}

\section{Study Selection and Characteristics}

A total of 2296 articles were identified, 153 were assessed with respect to their eligibility for inclusion (Supplemental Table 6), and 27 studies were included in the systematic review (Fig 1) (Table 1). ${ }^{17-43}$ These 27 studies included 484 fetuses with isolated ACC and no other associated CNS and/or extra-CNS anomalies at first prenatal assessment.

Quality assessment of the included studies was performed by using NOS for cohort studies. ${ }^{44}$ Some of the included studies showed an overall good rate as regard for the selection and comparability of the study groups and for the ascertainment of the outcome of interest. The main weaknesses of these studies were represented by their retrospective design, small sample size , and lack of a standardized postnatal confirmation. Furthermore, the relatively short period of follow-up after birth did not allow a precise estimation of the overall rate of additional anomalies detected only after birth and missed prenatally.

\section{Synthesis of the Results}

CACC

Twenty studies including 261 fetuses with isolated cACC were included in this systematic review.

The rate of chromosomal anomalies was $4.81 \%$ (95\% confidence interval [CI], 2.2-8.4) (Fig 2, Table 3). The figures for the different chromosomal anomalies found in fetuses with isolated cACC are shown in Supplemental Table 7.

It was not possible to extrapolate data for the rate of clinically significant CNVs in fetuses with isolated cACC and normal karyotype, thus the occurrence of clinically significant CNVs was assessed in fetuses with either cACC or pACC.

Overall, the rate of significant CNVs in fetuses with isolated ACC (either cACC or pACC) and normal karyotype was 5.74\% (95\% CI, 1.3-13.1) (Fig 2)

In $2.99 \%$ (95\% CI, 0.9-6.1) of the cases, prenatal diagnosis failed in correctly identifying cACC, with some of the cases of pACC misdiagnosed as having cACC (Supplemental Fig 5).

Additional anomalies not detected at prenatal ultrasound were diagnosed at fetal MRI in 7.83\% (95\% CI, 1.2-19.6) of the cases, whereas the rate of additional structural anomalies diagnosed only after birth and missed at prenatal evaluation was 5.49\% (95\% CI, 2.4-9.7) (Table 3, Supplemental Figs 6 and 7). Individual case descriptions of the anomalies detected only at fetal MRI and postnatal imaging/ clinical investigation are shown in Supplemental Tables 8 and 9.

In view of the high heterogeneity in study design, age at and type of assessment, and time at follow-up, the rates for abnormal neurodevelopmental outcomes might not reflect the actual neuropsychological performance of these children and should be interpreted with caution. Furthermore, it was not possible to ascertain the neurodevelopmental performance of children with either normal standard full karyotype and no CNVs on CMA because only one study reported this outcome. Neurodevelopmental outcome was reported to be normal in 76.04\% (95\% CI, 64.3-86.1) of children with a prenatal diagnosis of isolated cACC confirmed at birth (Fig 3, Table 4). The rates of borderline/moderate and severe neurodevelopmental outcome in these children was $16.04 \%$ (95\% CI, 7.6-26.8,) and 8.15\% (95\% CI, $2.5-16.8$ ) respectively. Table 3 shows the detailed figures for the abnormal neurodevelopmental performance in children with isolated cACC. Gross and fine motor control were affected in 4.40\% (95\% CI0.6-11.3) and $10.98 \%$ (95\% CI 4.1-20.6) of the cases, whereas $6.80 \%$ (95\% CI, 1.7-14.9) of these children presented with epilepsy. Cognitive status was affected in 15.16\% (95\% CI, 6.925.9) of the cases, whereas language impairment was affected in 8.02\% (95\% CI, 2.1-17.3). Finally, abnormal ocular control and coordination occurred in $15.84 \%$ (95\% CI, 4.3-32.9) and $9.50 \%$ (95\% CI, 3.2-18.7) of the cases, respectively (Supplemental Fig 8).

Individual outcome descriptions of children with isolated cACC showing abnormal neurodevelopmental profiles are shown in Supplemental Table 10 .

\section{pACC}

Fifteen studies including 225 fetuses with pACC were included in this review.

The rate of chromosomal anomalies in fetuses with pACC and no other structural anomalies visible at prenatal imaging was 7.45\% (95\% 

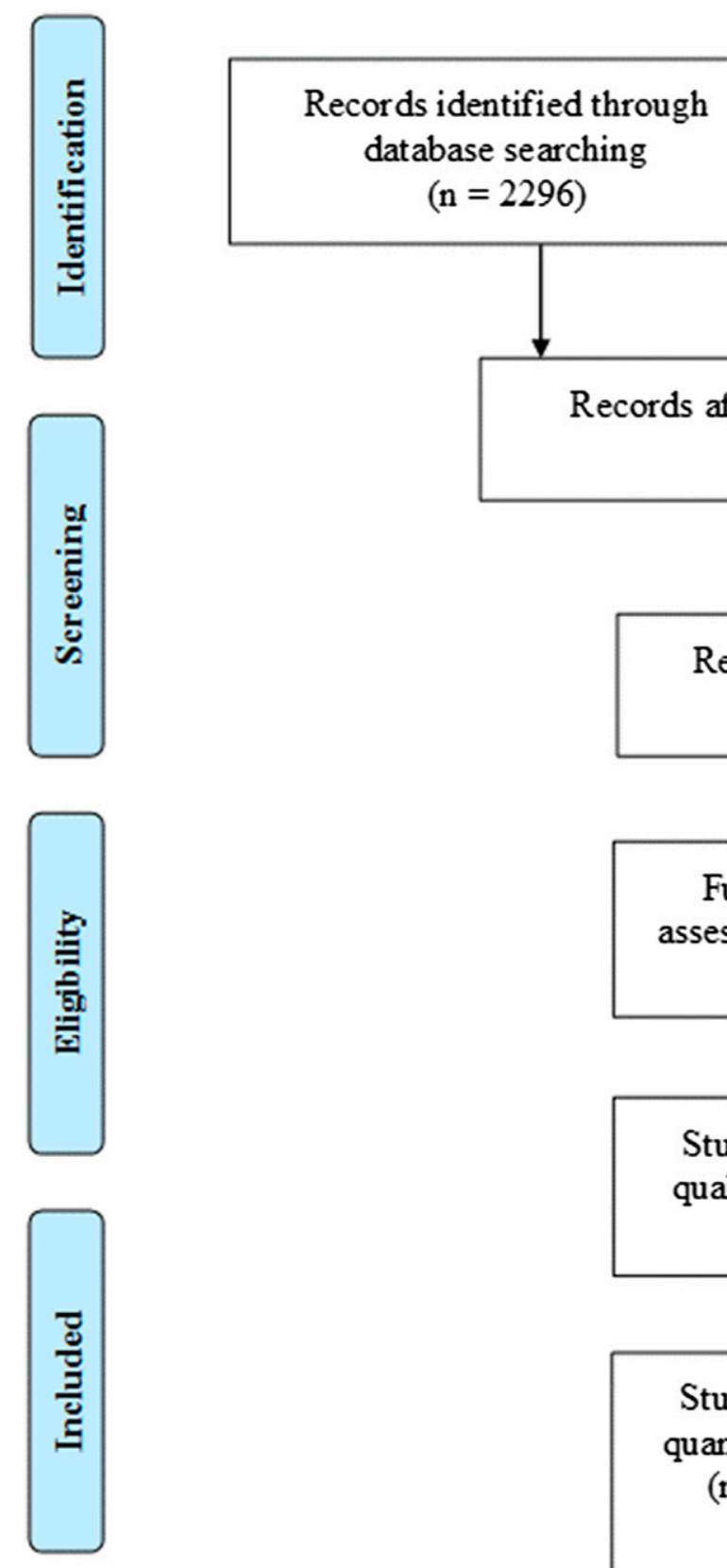

$(\mathrm{n}=2296)$

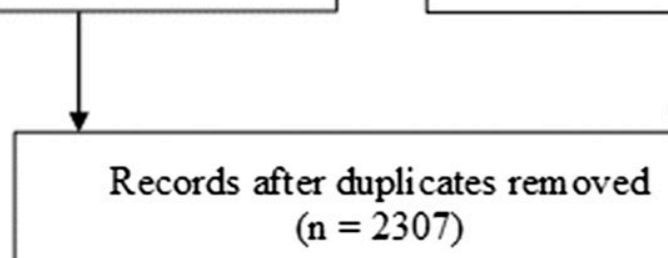

Additional records identified through other sources $(\mathrm{n}=11)$

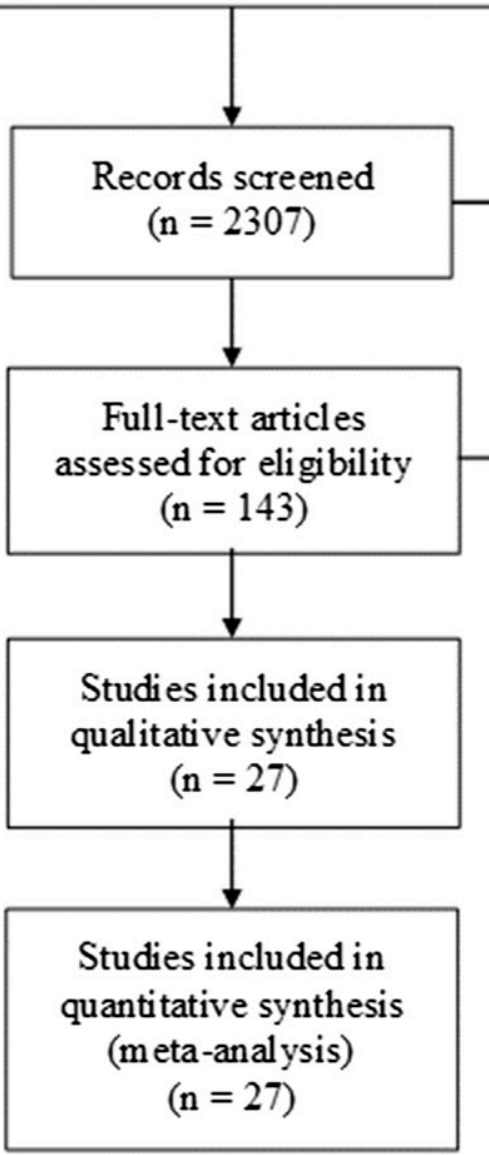

FIGURE 1

Systematic review flowchart.

CI, 2.0-15.9) (Fig 2, Table 4). The figures for the different chromosomal anomalies found in fetuses with isolated pACC are shown in Supplemental Table 11.

Additional anomalies not detected at prenatal ultrasound were diagnosed at fetal MRI in 11.86\% (95\% CI, 3.2-24.9) of the cases, whereas the rate of additional structural anomalies diagnosed only after birth and missed at prenatal evaluation was $14.46 \%$ (95\% CI, 6.7-24.6) (Table 4, Supplemental Figs 6 and 7). Individual case descriptions of the anomalies detected only at fetal MRI and postnatal imaging/ clinical investigation are shown in Supplemental Tables 12 and 13.

A discrepancy between prenatal and postnatal diagnosis of pACC occurred in $7.99 \%$ (95\% CI, 2.5-16.3) of the cases, mainly consisting in cases of hypoplastic or dysgenetic corpus callosum misdiagnosed as pACC (Supplemental Fig 5).

Assessment of neurodevelopmental outcome in children with isolated pACC was even more problematic in view of the smaller sample size analyzed compared with cACC. 
cACC

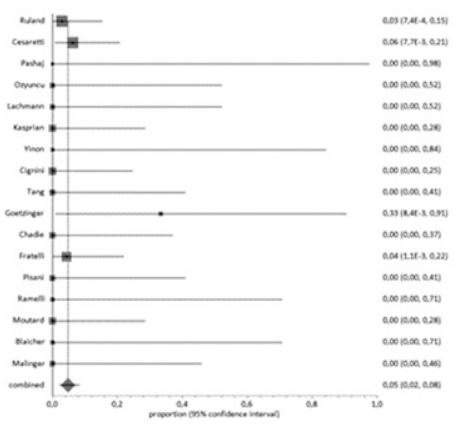

pACC

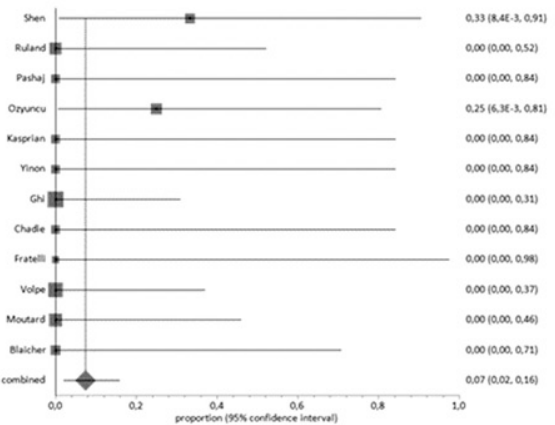

CMA

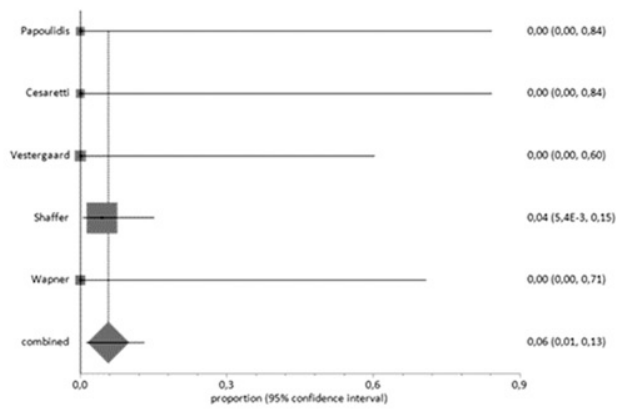

FIGURE 2

Pooled proportions for the occurrence of chromosomal anomalies and pathogenic CNVs in fetuses with CACC and pACC.
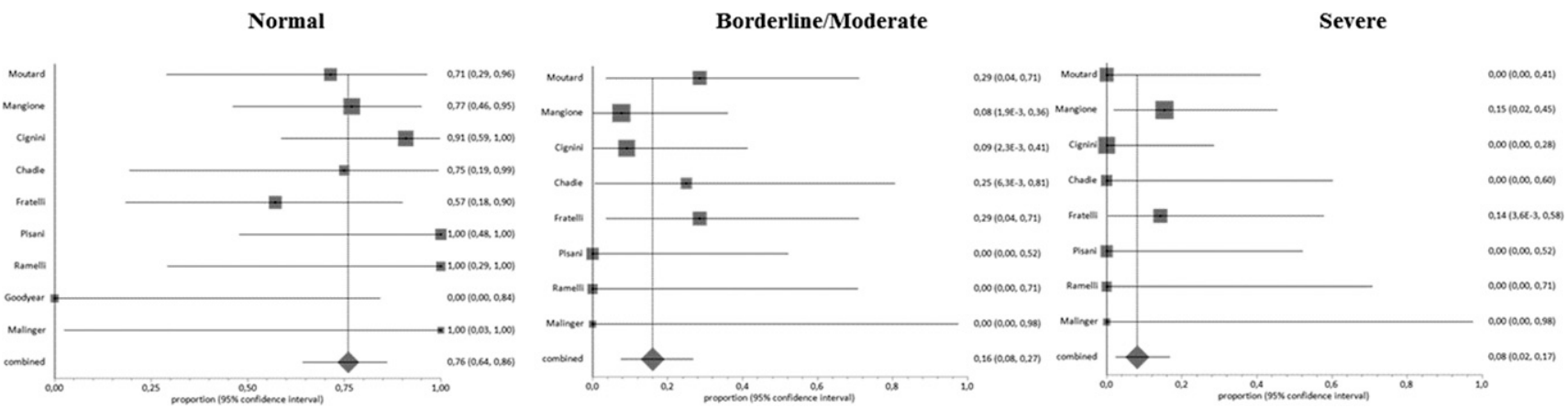

\section{FIGURE 3}

Pooled proportions for the occurrence of abnormal neurodevelopmental outcome in fetuses with cACC

Neurodevelopmental outcome was reported to be normal in $71.42 \%$ (95\% CI, 53.1-86.7) of children with a prenatal diagnosis of isolated pACC confirmed at birth (Table 4). The rates of borderline/moderate and severe neurodevelopmental outcomes in these children was $14.92 \%$ (95\% CI, 4.2-30.7) and $12.52 \%$ (95\% CI, 2.9-27.5), respectively (Fig 4).
Fine motor control was affected in 11.74 (95\% CI, $0.9-32.1$ ) of the cases, and $16.11 \%$ (95\% CI, 2.538.2) of these children presented with epilepsy. Cognitive status

TABLE 3 Pooled Proportions for the Outcomes Explored in This Systematic Review in Fetuses With cACC

\begin{tabular}{|c|c|c|c|c|c|}
\hline Outcome & No. of Studies $(n)$ & Fetuses $(n / M)$ & $1^{2}(\%)$ & Raw \% (95\% Cl) & Pooled Proportion (95\% Cl) \\
\hline \multicolumn{6}{|l|}{ Pregnancy Outcome } \\
\hline Chromosomal anomalies (standard karyotype) & 17 & $5 / 174$ & 0 & $2.87(0.9-6.6)$ & $4.81(2.2-8.4)$ \\
\hline Chromosomal microarray (CNVs) ${ }^{a}$ & 5 & $2 / 56$ & 0 & $3.57(0.4-12.3)$ & $5.74(1.3-13.1)$ \\
\hline Additional anomalies detected only at prenatal MRI & 8 & $5 / 99$ & 59.5 & $5.05(1.7-11.4)$ & $7.83(1.2-19.6)$ \\
\hline Additional anomalies detected only post-natally & 12 & $9 / 144$ & 45.9 & $6.25(2.9-11.5)$ & $5.49(2.4-9.7)$ \\
\hline Discrepancy between pre and post-natal diagnosis & 15 & $3 / 156$ & 0 & $1.92(0.4-5.5)$ & $2.99(0.9-6.1)$ \\
\hline \multicolumn{6}{|l|}{ Neurodevelopmental outcome } \\
\hline Normal & 9 & $41 / 53$ & 29.2 & $77.36(63.8-87.7)$ & $76.04(64.3-86.1)$ \\
\hline Borderline/Moderate & 8 & $7 / 51$ & 0 & $13.73(5.7-26.3)$ & $16.04(7.6-26.8)$ \\
\hline Severe & 8 & $3 / 51$ & 0 & $5.88(1.2-16.2)$ & $8.15(2.5-16.8)$ \\
\hline \multicolumn{6}{|l|}{ Detailed neurodevelopmental outcome } \\
\hline Gross motor & 8 & $1 / 51$ & 0 & $2.0(0.1-10.6)$ & $4.40(0.6-11.3)$ \\
\hline Fine motor & 7 & $5 / 50$ & 10.5 & $10.0(3.3-21.8)$ & $10.98(4.1-20.6)$ \\
\hline Cognitive & 7 & $7 / 50$ & 5 & $14.0(5.8-26.7)$ & $15.16(6.9-25.9)$ \\
\hline Epilepsy & 8 & $1 / 51$ & 0 & $2.0(0.1-10.6)$ & $6.80(1.7-14.9)$ \\
\hline Sensory & 7 & $0 / 50$ & 0 & $0(0-7.1)$ & $0(0-9.2)$ \\
\hline Visual & 7 & $5 / 50$ & 52.8 & $10.0(3.3-21.8)$ & $15.84(4.3-32.9)$ \\
\hline Coordination & 7 & $5 / 50$ & 47 & $10.0(3.3-21.8)$ & $9.50(3.2-18.7)$ \\
\hline Language & 6 & $4 / 45$ & 48.3 & $8.89(2.5-21.2)$ & $8.02(2.1-17.3)$ \\
\hline
\end{tabular}

a The analysis included cases with either isolated cACC and pACC. 
TABLE 4 Pooled Proportions for the Outcomes Explored in This Systematic Review in Fetuses With pACC

\begin{tabular}{|c|c|c|c|c|c|}
\hline Outcome & No. of Studies $(n)$ & Fetuses $(n / M)$ & $\mathrm{I}^{2}(\%)$ & Raw \% (95\% Cl) & Pooled Proportion (95\% Cl) \\
\hline \multicolumn{6}{|l|}{ Pregnancy outcome } \\
\hline Chromosomal anomalies (standard karyotype) & 12 & $2 / 48$ & 0 & $4.17(0.5-14.3)$ & $7.45(2.0-15.9)$ \\
\hline Chromosomal microarray $(C N V s)^{a}$ & 5 & $2 / 56$ & 0 & $3.57(0.4-12.3)$ & $5.74(1.3-13.1)$ \\
\hline Additional anomalies detected only at prenatal MRI & 8 & $3 / 29$ & 38.7 & $10.34(2.2-27.4)$ & $11.86(3.2-24.9)$ \\
\hline Additional anomalies detected only postnatally & 10 & $7 / 53$ & 1.3 & $13.21(5.5-25.3)$ & $14.46(6.7-24.6)$ \\
\hline Discrepancy between prenatal and postnatal diagnosis & 9 & $3 / 53$ & 0 & $5.66(1.2-15.7)$ & $7.99(2.5-16.3)$ \\
\hline \multicolumn{6}{|l|}{ Neurodevelopmental outcome } \\
\hline Normal & 7 & $17 / 23$ & 0 & $7.39(5.2-9.0)$ & $71.42(53.1-86.7)$ \\
\hline Borderline/moderate & 7 & $3 / 23$ & 0 & $13.04(2.8-33.6)$ & $14.92(4.2-30.7)$ \\
\hline Severe & 7 & $2 / 23$ & 0 & $8.70(1.1-28.0)$ & $12.52(2.9-27.5)$ \\
\hline \multicolumn{6}{|l|}{ Detailed neurodevelopmental outcome } \\
\hline Gross motor & 4 & $0 / 13$ & 0 & $0(0-24.7)$ & $0(0-23.0)$ \\
\hline Fine motor & 4 & $1 / 13$ & 0 & $7.70(0.2-3.6)$ & $11.74(0.9-32.1)$ \\
\hline Cognitive & 4 & $2 / 13$ & 42.2 & $15.38(1.9-45.4)$ & $17.25(3.0-39.7)$ \\
\hline Epilepsy & 4 & $2 / 13$ & 19.4 & $15.38(1.9-45.4)$ & $16.11(2.53 .2)$ \\
\hline Sensory & 4 & $0 / 13$ & 0 & $0(0-24.7)$ & $0(0-23.0)$ \\
\hline Visual & 4 & $0 / 13$ & 0 & $0(0-24.7)$ & $0(0-23.0)$ \\
\hline Coordination & 4 & $1 / 13$ & 0 & $7.70(0.2-3.6)$ & $11.74(0.9-32.1)$ \\
\hline Language & 4 & $2 / 13$ & 42.2 & $15.38(1.9-45.4)$ & $17.25(3.0-39.7)$ \\
\hline
\end{tabular}

a The analysis included cases with either isolated completed and partial ACC.
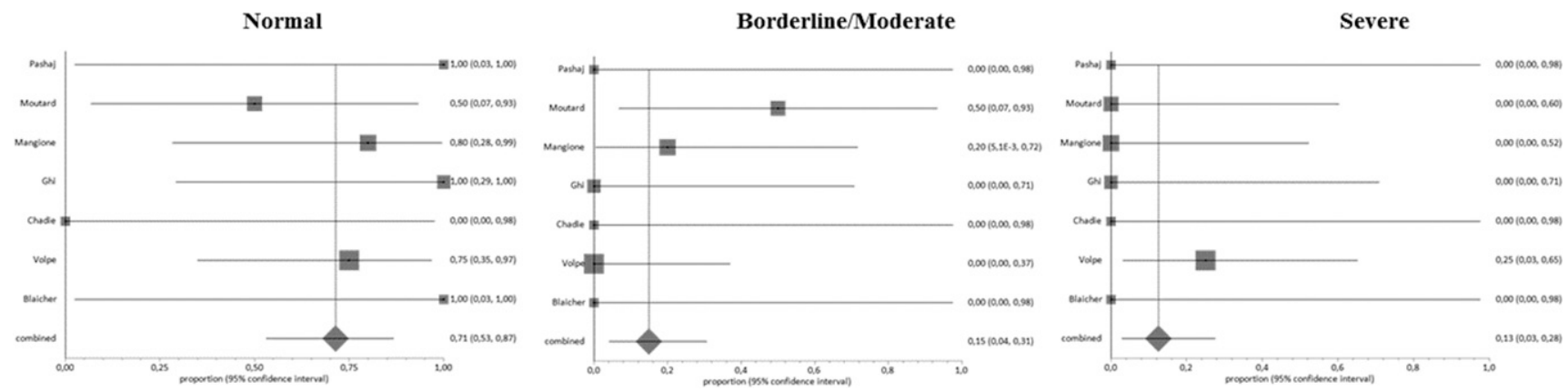

FIGURE 4

Pooled proportions for the occurrence of abnormal neurodevelopmental outcome in fetuses with pACC

was affected in $17.25 \%(95 \% \mathrm{CI}$, 3.0-39.7) of the cases, whereas language impairment was noticed in $17.25 \%$ (95\% CI, 3.0-39.7) of the cases. Finally, abnormal coordination occurred in $11.74 \%$ (95\% CI, 0.932.1) of the cases (Supplemental Fig 9).

Individual outcome descriptions of children with isolated pACC showing abnormal neurodevelopmental profile are shown in Supplemental Table 14.

\section{DISCUSSION}

\section{Summary of Evidence}

The findings from this systematic review showed that fetuses with isolated callosal agenesis (either cACC or pACC) are at high risk of chromosomal anomalies. Even when standard karyotyping is normal, there is still a significant risk of genetic anomalies detected only at CMA analysis. In cases of a prenatal diagnosis of isolated ACC, the risk of associated anomalies detected only at fetal MRI is about $8 \%$ and $12 \%$ in fetuses with cACC and pACC, respectively, whereas associated anomalies detected only after birth can occur in about 5\% of fetuses with cACC and in 14\% of those with pACC. Short periods of follow-up, heterogeneity in imaging protocols, neurodevelopmental tools used, discrepancies in the definition of abnormal outcome, and the small number of included cases did not allow us to draw any robust conclusions regarding the occurrence of abnormal neurodevelopmental outcome in children with a prenatal diagnosis of isolated callosal agenesis. The findings from this systematic review suggested that about two-thirds of children showed a normal neurodevelopmental outcome, although fine and gross motor control, coordination, language, and cognitive status can be impaired in a significant proportion of these children. However, these figures might not reflect the actual burden of neuropsychological morbidity in children with isolated ACC; additional large prospective 
studies are needed to confirm these findings.

\section{Strengths and Limitations}

The strengths of this study are its robust methodology to identify all possible studies, assess data quality, and synthesize all suitable data.

For several meta-analyses, the number of included studies was small and some studies included small numbers. The assessment of the potential publication bias was also problematic, either because of the outcome nature (rates with the left side limited to the value 0 ), which limits the reliability of funnel plots, or because of the scarce number of individual studies, which strongly limits the reliability of formal tests. Furthermore, all the studies included were retrospective, and thus liable to a considerable risk of selection bias. In addition, several outcomes and associations were not adequately reported in many studies. Finally, because of the relatively short postnatal follow-up period, the overall rate of additional anomalies detected only after birth and missed prenatally may have been underestimated.

The assessment of neurodevelopmental outcome in children with a prenatal diagnosis of isolated ACC was also problematic; differences in age at follow-up and neurodevelopmental tools used did not allow a meaningful stratification of the different outcomes measures; therefore, the figures for the developmental disabilities provided in the current review might not reflect the actual burden of neuropsychological comorbidities associated with isolated ACC and should be interpreted with caution. Furthermore, it was not possible to stratify the analysis including only fetuses with normal standard full karyotype and no pathogenic CNVs detected at CMA in view of the lack of data regarding the neurodevelopmental outcome in these studies. In this scenario, it might be entirely possible that cases with isolated ACC, normal standard karyotype, and pathogenic CNVs were included in the analysis, thus biasing the results. Finally, the majority of the included studies did not report a detailed description of the neurologic performance of fetuses with isolated ACC and merely stratified the analysis in 3 different categories (normal, borderline/ moderate, and severe), for which inclusion criteria differed among the studies. In view of all these limitations, the resulting summary measures need to be treated with some caution.

Despite all of these limitations, our review represents the most up-to-date overall assessment of the neurodevelopmental outcome in callosal agenesis diagnosed prenatally; this is important because counseling for parents based on single, small studies that are subject to publication bias may be inadequate.

\section{Implication for Clinical Practice and Future Perspectives}

Advances in prenatal imaging techniques have led to an increase in the diagnostic accuracy of ultrasound in detecting callosal anomalies.

However, prenatal counseling when a fetus is diagnosed with ACC is challenging.

The findings from this systematic review showed that chromosomal anomalies can occur in a significant proportion of fetuses with isolated ACC; furthermore, the risk of genetic anomalies not detected by conventional karyotyping is also not negligible. CMA has recently been shown to provide useful information in patients with learning disabilities and congenital anomalies for which conventional cytogenetic tests have proven negative. The findings from this review support the use of CMA when ACC is diagnosed prenatally. ${ }^{48}$
Fetal MRI is usually performed in cases of prenatal diagnosis of ACC. In the current review, associated anomalies not detected at ultrasound were diagnosed in 7.83\% (95\% CI, 1.2-19.6) and in $11.86 \%$ (95\% CI, 3.2-24.9) in cACC and pACC, respectively. However, even in cases of a prenatal diagnosis of isolated anomaly, the risk of ACC being not truly isolated is relatively high, with additional anomalies detected only at postnatal imaging and/or clinical examination, but missed prenatally, occurring in 5.49\% (95\% confidence interval [CI], 2.4-9.7) and 14.46\% (95\% confidence interval [CI], 6.724.6) of fetuses with pACC and cACC, respectively.

Quantifying the real contribution of fetal MRI in brain anomalies is challenging. Several factors, such as operator's experience, imaging protocol, time and type of assessment, interval between ultrasound and MRI, and type of anomaly, may play a role in this scenario and explain the wide heterogeneity and the conflicting results reported in previously published studies. Despite all these controversies, MRI is routinely used in clinical practice to confirm diagnosis and to look for associated anomalies. The large majority of additional anomalies detected only at fetal MRI involved neuronal migration disorders (Supplemental Tables 8 and 12), which can be detected preferentially from the third trimester of pregnancy. On this basis, when MRI is performed at the time of the anomaly scan to confirm diagnosis, it might be reasonable to arrange a follow-up scan in the third trimester to ascertain whether ACC is truly isolated. These suggestions are based on the authors' experience and further studies looking at the optimal timing of fetal MRI are needed to confirm these findings.

Furthermore, even when prenatal diagnosis rules out associated anomalies, there is still a significant 
risk $(5.5 \%$ and $14.5 \%$ in fetuses with cACC and pACC, respectively) to detect additional anomalies after birth (Supplemental Tables 8 and 12). This should be stressed during antenatal counseling, underlying the fact that prenatal imaging is not always able to differentiate between complex and isolated cases, and that postnatal imaging and a thorough clinical examination are necessary to confirm that ACC is truly isolated.

Assessing the neurodevelopmental profile in children with ACC is challenging. The term neurodevelopmental outcome can be misleading and inappropriate when dealing with brain anomalies because it encompasses a wide spectrum of signs with different underlying disorders and pathologic processes that are not always easily measured and that represent a continuous interaction between pathologic, environmental, and adaptive factors. Intellectual abilities in individuals with ACC have been reported to be in the lower range of normal; furthermore, difficulties in pragmatic language skills and mathematics, expressive and receptive language, visual and spatial reasoning, and attentional skills are impaired or compromised in a significant proportion of children. ${ }^{5}$ However, postnatal studies are biased by the fact that only symptomatic patients are included, thus potentially overestimating the burden of disabilities observed in these anomalies.

The findings from this systematic review confirmed these results and showed that children with ACC may present different degrees of impairment in neurologic and neuropsychological domains.
Although a direct comparison of the neurodevelopmental and psychological performance of children with cACC compared with those with pACC was not performed in view of the design of most of the included studies, which did not allow such a comparison, the findings of this review do not suggest a huge difference between the 2 different entities of callosal agenesis. The results from this meta-analysis are surprising and disagree with what is observed after birth, where pACC is less likely to be diagnosed as an isolated finding and is usually affected by higher rates of neurodevelopmental disabilities compared with cACC. In the collective authors' opinion, the relatively high rate of favorable outcome observed in pACC might be due to the fact that many of the cases labeled as pACC prenatally are diagnosed after birth as having hypoplasia of the corpus callosum.

\section{CONCLUSIONS}

Fetuses with isolated callosal agenesis are at high risk of chromosomal anomalies even when a standard karyotype is negative. Prenatal imaging is not able to completely rule out associated anomalies usually coexisting with this condition, and the risk of ACC of being not truly isolated after birth is significant.

In isolated callosal agenesis, anomalies in fine and gross motor control, coordination, language, cognitive status, and intelligence can occur in a significant proportion of children. However, in view of the small number of included cases, short period of follow-up, and heterogeneity of neurodevelopmental tools adopted, these results should be interpreted with caution, and future large prospective studies aiming at assessing the neurodevelopmental and psychological performance of children with isolated callosal agenesis using standardized tools of neurodevelopmental assessment at appropriate time intervals are needed to ascertain the actual neuropsychological performance and intellectual impairment of children with isolated ACC.

\section{ACKNOWLEDGMENTS}

We thank Prof O. Glenn, Prof J. Barkovic, Prof L. Chitty, Prof G. Kasprian, Prof D. Prayer, Prof Berg, Prof V. D’Addario, Prof P. Volpe, Prof G. Rizzo, Prof M. Kilby, Dr A. Rueland, Prof TA Huisman, Dr O. Shen, Prof W. Brown, Dr A Yazıcıoğlu, Prof PH Tang, Dr F. Hadzagic-Catibusic, Dr. H Slater, Dr M. Yamasaki, Dr F. Scott, Dr Y. Yinon, Dr M. Nanni, Dr A. Knafel, Dr L. Kleeman, Dr S. Pashaj, Dr F. Scott, Dr E.M. Vestergaard, Dr G. Srebniak, Dr S. Toru, and Dr I Papoulidis for their contribution to this systematic review in terms of additional data supplied and support.

\section{ABBREVIATIONS}

ACC: agenesis of the corpus callosum

cACC: complete agenesis of the corpus callosum

$\mathrm{CI}$ : confidence interval

CMA: chromosomal microarray

CNS: central nervous system

CNV: copy number variation

NOS: Newcastle-Ottawa Scale

pACC: partial agenesis of the corpus callosum 
helped to interpret the results, and wrote the manuscript; Profs Acharya and Papageorghiou conceptualized and designed the study and drafted the initial manuscript; Dr Leombroni and Prof Manzoli performed the statistical analysis and critically reviewed the manuscript; Dr Prefumo designed the study and the data collection instruments, coordinated and supervised data collection at 2 of the 4 sites, and critically reviewed the manuscript; and all authors approved the final manuscript as submitted.

DOI: $10.1542 /$ peds.2016-0445

Accepted for publication Jun 16, 2016

Address correspondence to Francesco D’Antonio, MD, PhD, Department of Clinical Medicine, Faculty of Health Sciences, UiT - The Arctic University of Norway, Hansine Hansens veg 18, 9019 Tromsø, Norway. E-mail: francesco.dantonio@uit.no

PEDIATRICS (ISSN Numbers: Print, 0031-4005; Online, 1098-4275)

Copyright (C) 2016 by the American Academy of Pediatrics

FINANCIAL DISCLOSURE: The authors have indicated they have no financial relationships relevant to this article to disclose.

FUNDING: No external funding.

POTENTIAL CONFLICTS OF INTEREST: The authors have indicated they have no potential conflicts of interest to disclose.

\section{REFERENCES}

1. Paul LK, Brown WS, Adolphs R, et al. Agenesis of the corpus callosum: genetic, developmental and functional aspects of connectivity. Nat Rev Neurosci. 2007;8(4):287-299

2. Glass HC, Shaw GM, Ma C, Sherr EH. Agenesis of the corpus callosum in California 1983-2003: a populationbased study. Am J Med Genet A. 2008;146A(19):2495-2500

3. Jeret JS, Serur D, Wisniewski K, Fisch C. Frequency of agenesis of the corpus callosum in the developmentally disabled population as determined by computerized tomography. Pediatr Neurosci. 1985-1986;12(2):101-103

4. Palmer EE, Mowat D. Agenesis of the corpus callosum: a clinical approach to diagnosis. Am J Med Genet C Semin Med Genet. 2014;166C(2):184-197

5. Siffredi V, Anderson V, Leventer RJ, Spencer-Smith MM. Neuropsychological profile of agenesis of the corpus callosum: a systematic review. Dev Neuropsychol. 2013;38(1):36-57

6. Schaefer GB, Bodensteiner JB. Evaluation of the child with idiopathic mental retardation. Pediatr Clin North Am. 1992;39(4):929-943

7. Hardan AY, Pabalan M, Gupta N, et al. Corpus callosum volume in children with autism. Psychiatry Res. 2009;174(1):57-61

8. Tibbo P, Nopoulos P, Arndt S, Andreasen NC. Corpus callosum shape and size in male patients with schizophrenia. Biol Psychiatry. 1998;44(6):405-412
9. Hynd GW, Semrud-Clikeman M, Lorys AR, Novey ES, Eliopulos D, Lyytinen H. Corpus callosum morphology in attention deficit-hyperactivity disorder: morphometric analysis of MRI. J Learn Disabil. 1991;24(3):141-146

10. de Wit MC, Srebniak MI, Govaerts LC, Van Opstal D, Galjaard RJ, Go AT. Additional value of prenatal genomic array testing in fetuses with isolated structural ultrasound abnormalities and a normal karyotype: a systematic review of the literature. Ultrasound Obstet Gynecol. 2014;43(2):139-146

11. Kearney HM, Thorland EC, Brown KK, Quintero-Rivera F, South ST; Working Group of the American College of Medical Genetics Laboratory Quality Assurance Committee. American College of Medical Genetics standards and guidelines for interpretation and reporting of postnatal constitutional copy number variants. Genet Med. 2011;13(7):680-685

12. Raybaud C. The corpus callosum, the other great forebrain commissures, and the septum pellucidum: anatomy, development, and malformation. Neuroradiology. 2010;52(6):447-477

13. Sotiriadis A, Makrydimas G. Neurodevelopment after prenatal diagnosis of isolated agenesis of the corpus callosum: an integrative review. Am J Obstet Gynecol. 2012;206(4):337. e1-337.e5

14. Henderson LK, Craig JC, Willis NS, Tovey D, Webster AC. How to write a Cochrane systematic review. Nephrology (Carlton). 2010;15(6):617-624
15. NHS Centre for Reviews and Dissemination. Systematic reviews: CRD's guidance for undertaking reviews in health care. York, United Kingdom: University of York; 2009

16. PRISMA statement. Available at: www. prisma-statement.org/. Accessed November 12, 2015

17. Cesaretti C, Nanni M, Ghi T, et al Variability of forebrain commissures in callosal agenesis: a prenatal MR imaging study. AJNR Am J Neuroradiol. 2016:37(3):521-527

18. Rüland AM, Berg C, Gembruch U, Geipel A. Prenatal diagnosis of anomalies of the corpus callosum over a 13-year period. Ultraschall Med. 2015. doi: 10.1055/s-0034-1399699

19. Papoulidis I, Sotiriadis A, Siomou $E$, et al. Routine use of array comparative genomic hybridization (aCGH) as standard approach for prenatal diagnosis of chromosomal abnormalities. Clinical experience of 1763 prenatal cases. Prenat Diagn. 2015;35(13):1269-1277

20. Shen 0, Gelot AB, Moutard ML, Jouannic JM, Sela HY, Garel C. Abnormal shape of the cavum septi pellucidi: an indirect sign of partial agenesis of the corpus callosum. Ultrasound Obstet Gynecol. 2015;46(5):595-599

21. Pashaj S, Merz E. Detection of fetal corpus callosum abnormalities by means of 3D ultrasound. UItraschall Med. 2016:37(2) 185-194

22. Ozyüncü 0, Yazıc10 ğlu A, Turğal M. Antenatal diagnosis and outcome 
of agenesis of corpus callosum:

A retrospective review of 33

cases. J Turk Ger Gynecol Assoc. 2014;15(1):18-21

23. Lachmann R, Sodre D, Barmpas M, Akolekar R, Nicolaides KH. Midbrain and falx in fetuses with absent corpus callosum at 11-13 weeks. Fetal Diagn Ther. 2013;33(1):41-46

24. Kasprian G, Brugger PC, Schöpf V, et al. Assessing prenatal white matter connectivity in commissural agenesis. Brain. 2013;136 (Pt 1):168-179

25. Yinon Y, Katorza E, Nassie DI, et al. Late diagnosis of fetal central nervous system anomalies following a normal second trimester anatomy scan. Prenat Diagn. 2013;33(10):929-934

26. Vestergaard EM, Christensen R, Petersen 0, Vogel I. Prenatal diagnosis: array comparative genomic hybridization in fetuses with abnormal sonographic findings. Acta Obstetricia et Gynecologica Scandinavica . 2013;92(7):762-768

27. Moutard ML, Kieffer V, Feingold $J$, et al. Isolated corpus callosum agenesis: a ten-year follow-up after prenatal diagnosis (how are the children without corpus callosum at 10 years of age?). Prenat Diagn. 2012;32(3):277-283

28. Wapner RJ, Martin CL, Levy B, et al. Chromosomal microarray versus karyotyping for prenatal diagnosis. N Engl J Med. 2012;367 (23):2175-2184

29. Yamasaki M, Nonaka M, Bamba Y, Teramoto C, Ban C, Pooh RK. Diagnosis, treatment, and long-term outcomes of fetal hydrocephalus. Semin Fetal Neonatal Med. 2012;17 (6):330-335

30. Shaffer LG, Rosenfeld JA, Dabell MP, et al. Detection rates of clinically significant genomic alterations by microarray analysis for specific anomalies detected by ultrasound. Prenat Diagn. 2012;32(10):986-995

31. Mangione R, Fries N, Godard P, et al. Neurodevelopmental outcome following prenatal diagnosis of an isolated anomaly of the corpus callosum. Ultrasound Obstet Gynecol. 2011;37(3):290-295

32. Ghi T, Carletti A, Contro E, et al. Prenatal diagnosis and outcome of partial agenesis and hypoplasia of the corpus callosum. Ultrasound Obstet Gynecol. 2010;35(1):35-41

33. Cignini P, D’Emidio L, Padula F, et al. The role of ultrasonography in the diagnosis of fetal isolated complete agenesis of the corpus callosum: a long-term prospective study. J Matern Fetal Neonatal Med. 2010;23(12):1504-1509

34. Tang PH, Bartha Al, Norton ME, Barkovich AJ, Sherr EH, Glenn OA. Agenesis of the corpus callosum: an MR imaging analysis of associated abnormalities in the fetus. AJNR Am J Neuroradiol. 2009;30(2):257-263

35. Goetzinger KR, Stamilio DM, Dicke JM, Macones GA, Odibo A0. Evaluating the incidence and likelihood ratios for chromosomal abnormalities in fetuses with common central nervous system malformations. Am J Obstet Gynecol. 2008;199(3):285.e1-285.e6

36. Chadie A, Radi S, Trestard L, et al; Haute-Normandie Perinatal Network. Neurodevelopmental outcome in prenatally diagnosed isolated agenesis of the corpus callosum. Acta Paediatr. 2008;97 (4):420-424

37. Fratelli N, Papageorghiou AT, Prefumo F, Bakalis S, Homfray T, Thilaganathan B. Outcome of prenatally diagnosed agenesis of the corpus callosum. Prenat Diagn. 2007;27 (6):512-517

38. Francesco P, Maria-Edgarda B, Giovanni P, Dandolo G, Giulio B. Prenatal diagnosis of agenesis of corpus callosum: what is the neurodevelopmental outcome? Pediatr Int. 2006;48(3):298-304

39. Ramelli G, Zanda N, Wyttenbach M, Bronz $L$, Schnider $A$. The prognosis of agenesis of the corpus callosum might mostly be favourable. Swiss Med Wkly. 2006;136(25-26) :404-405

40. Volpe P, Paladini D, Resta M, et al. Characteristics, associations and outcome of partial agenesis of the corpus callosum in the fetus. Ultrasound Obstet Gynecol. 2006;27 (5):509-516

41. Blaicher W, Prayer D, Mittermayer C, et al. Magnetic resonance imaging in foetuses with bilateral moderate ventriculomegaly and suspected anomaly of the corpus callosum on ultrasound scan. Ultraschall Med. 2003;24(4):255-260

42. Malinger G, Lerman-Sagie T, Watemberg N, Rotmensch S, Lev D, Glezerman M. A normal secondtrimester ultrasound does not exclude intracranial structural pathology. Ultrasound Obstet Gynecol. 2002;20(1):51-56

43. Goodyear PW, Bannister CM, Russell S, Rimmer S. Outcome in prenatally diagnosed fetal agenesis of the corpus callosum. Fetal Diagn Ther. 2001;16(3):139-145

44. Wells GA, Shea B, O'Connell D, et al. The Newcastle-Ottawa Scale for assessing the quality of nonrandomised studies in meta-analyses. Available at: www.ohri.ca/programs/clinical_ epidemiology/oxford.asp

45. Hunter JP, Saratzis A, Sutton AJ, Boucher RH, Sayers RD, Bown MJ. In meta-analyses of proportion studies, funnel plots were found to be an inaccurate method of assessing publication bias. J Clin Epidemiol. 2014;67 (8):897-903

46. Egger M, Davey Smith G, Schneider M, Minder C. Bias in meta-analysis detected by a simple, graphical test. BMJ. 1997;315(7109):629-634

47. Higgins JPT, Green S, eds. Cochrane Handbook for Systematic Reviews of Interventions. Version 5.0.2. The Cochrane Collaboration, 2011. Available at: www.cochrane-handbook. org. Accessed December 10, 2015

48. Sagoo GS, Butterworth AS, Sanderson S, Shaw-Smith C, Higgins JP, Burton H. Array CGH in patients with learning disability (mental retardation) and congenital anomalies: updated systematic review and meta-analysis of 19 studies and 13,926 subjects. Genet Med. 2009;11(3):139-146 


\section{Outcomes Associated With Isolated Agenesis of the Corpus Callosum: A Meta-analysis}

Francesco D'Antonio, Giorgio Pagani, Alessandra Familiari, Asma Khalil, Tally-Lerman Sagies, Gustavo Malinger, Zvi Leibovitz, Catherine Garel, Marie Laure

Moutard, Gianluigi Pilu, Amar Bhide, Ganesh Acharya, Martina Leombroni, Lamberto Manzoli, Aris Papageorghiou and Federico Prefumo Pediatrics 2016;138; ; originally published online August 31, 2016; DOI: $10.1542 /$ peds. 2016-0445

\section{Updated Information \& Services \\ Supplementary Material}

References

Subspecialty Collections

Permissions \& Licensing

Reprints including high resolution figures, can be found at: /content/138/3/e20160445.full.html

Supplementary material can be found at: /content/suppl/2016/08/25/peds.2016-0445.DCSupplemental. html

This article cites 43 articles, 5 of which can be accessed free at: /content/138/3/e20160445.full.html\#ref-list-1

This article, along with others on similar topics, appears in the following collection(s):

Developmental/Behavioral Pediatrics /cgi/collection/development:behavioral_issues_sub

Cognition/Language/Learning Disorders

/cgi/collection/cognition:language:learning_disorders_sub Fetus/Newborn Infant

/cgi/collection/fetus:newborn_infant_sub

Birth Defects

/cgi/collection/birth_defects_sub

Information about reproducing this article in parts (figures, tables) or in its entirety can be found online at:

/site/misc/Permissions.xhtml

Information about ordering reprints can be found online: /site/misc/reprints.xhtml

PEDIATRICS is the official journal of the American Academy of Pediatrics. A monthly publication, it has been published continuously since 1948. PEDIATRICS is owned, published, and trademarked by the American Academy of Pediatrics, 141 Northwest Point Boulevard, Elk Grove Village, Illinois, 60007. Copyright ( 2016 by the American Academy of Pediatrics. All rights reserved. Print ISSN: 0031-4005. Online ISSN: 1098-4275. 


\section{Supplemental Information}

\section{FUNNEL PLOTS AND PUBLICATION BIAS}

Supplemental Figures 5-9, Pooled proportions for the detailed neurodevelopmental outcomes.

cACC

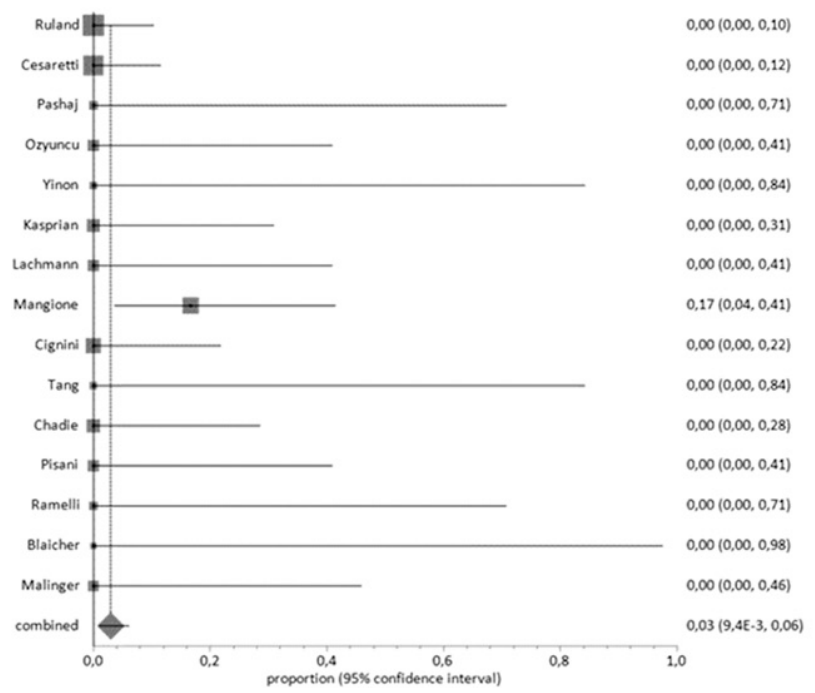

Supplemental Figures 10 and 12, Complete ACC, Chromosomal anomalies.

Supplemental Figures 13 and 14, Partial ACC, Chromosomal anomalies.

\section{pACC}

SUPPLEMENTAL FIGURE 5

Pooled proportions for the discrepancy between prenatal and postnatal diagnosis in fetuses with ACC.

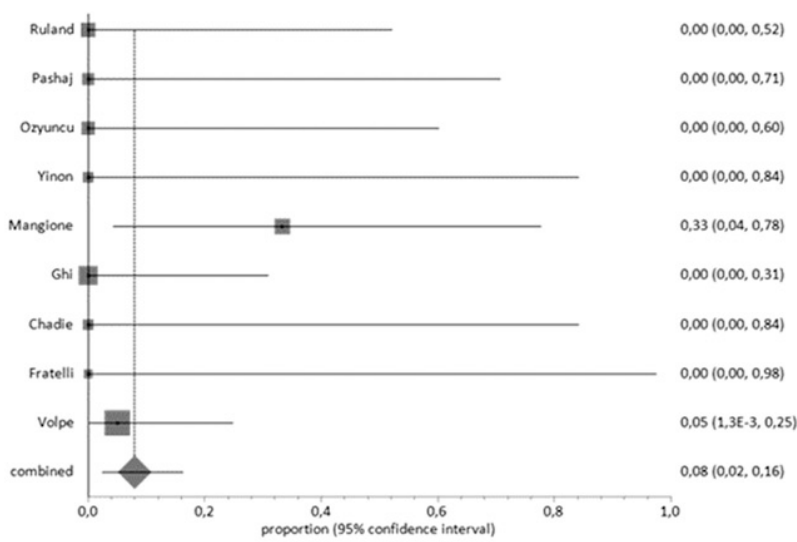

$0,0,0,0,0,0,10$

$0.00(0,00,0.60)$

$0,00(0,00,0,84)$

$3(0,04,0,78)$

$.00(0,00,0,31)$

$(0,0,0.84$

$.05(1,3 E-3,0,25)$

$0.08(0,02,0,16)$ 
cACC

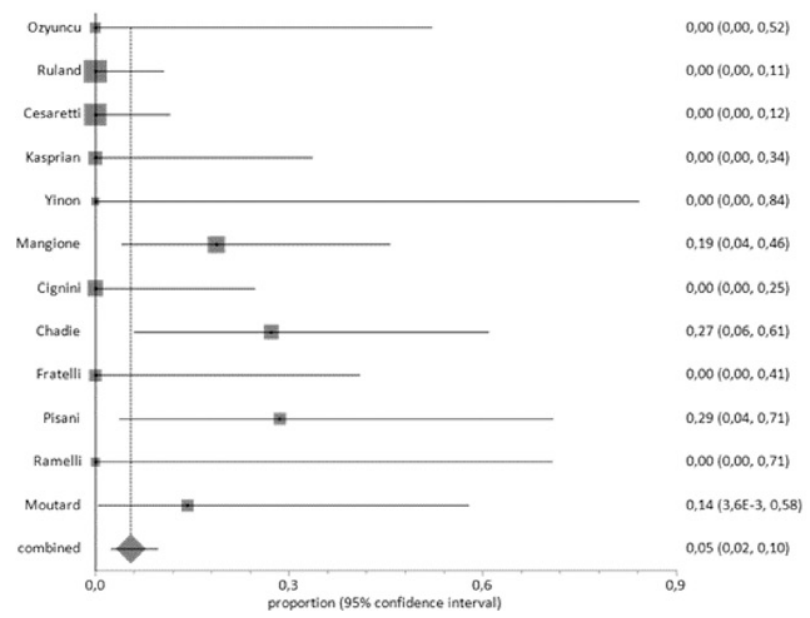

pACC

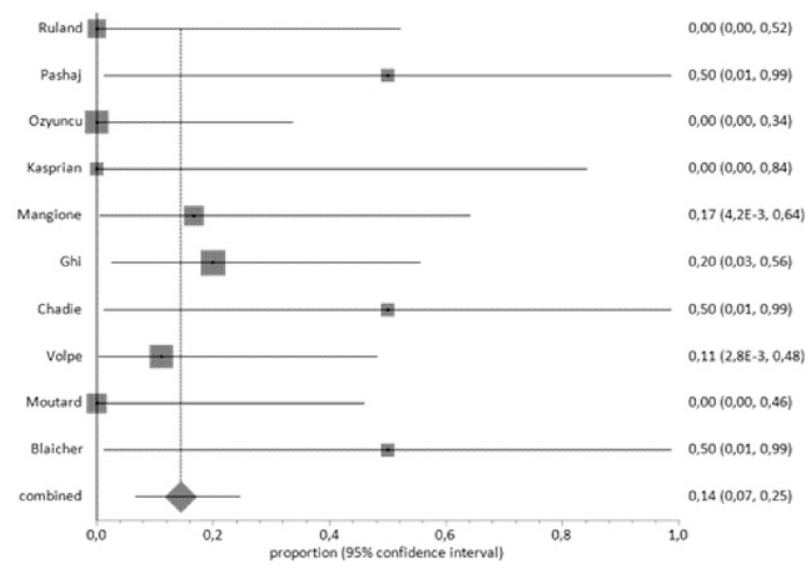

SUPPLEMENTAL FIGURE 6

Pooled proportions for the occurrence of additional anomalies detected only at fetal MRI in fetuses with a prenatal diagnosis of isolated ACC.

cACC

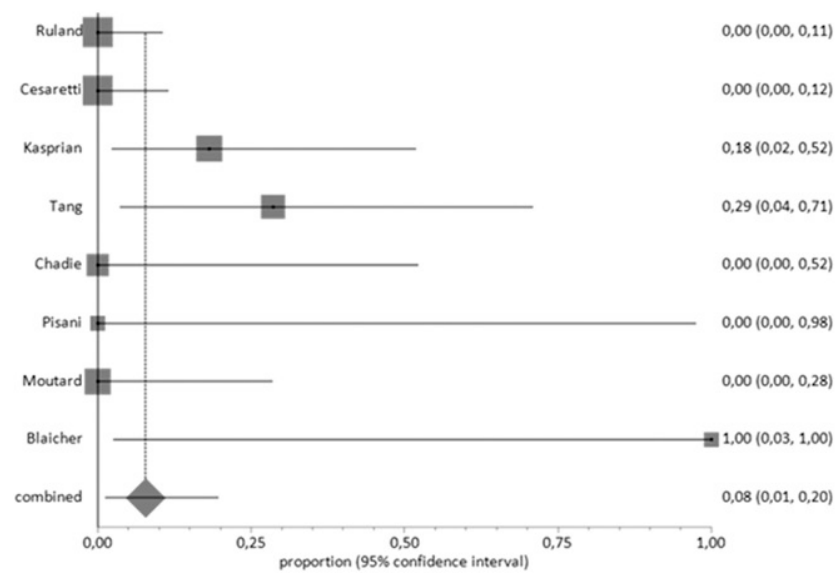

pACC

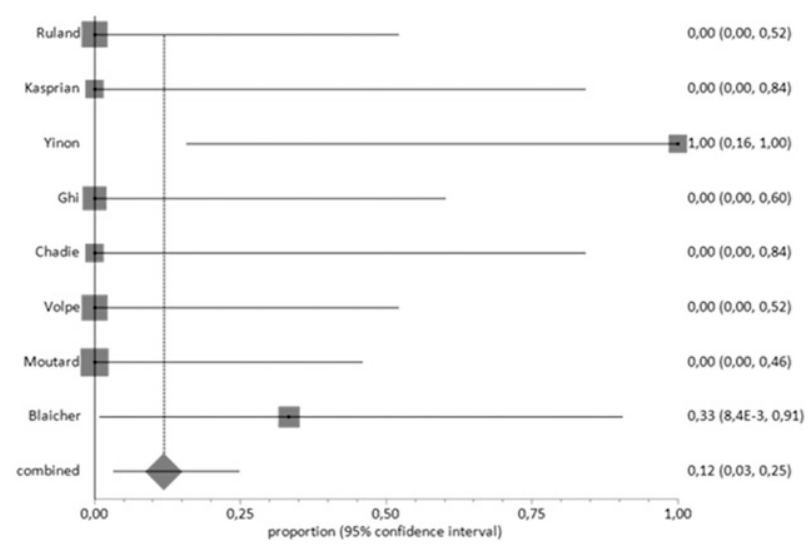

SUPPLEMENTAL FIGURE 7

Pooled proportions for the occurrence of additional anomalies detected only after birth in fetuses with a prenatal diagnosis of isolated ACC 
A

Gross motor control

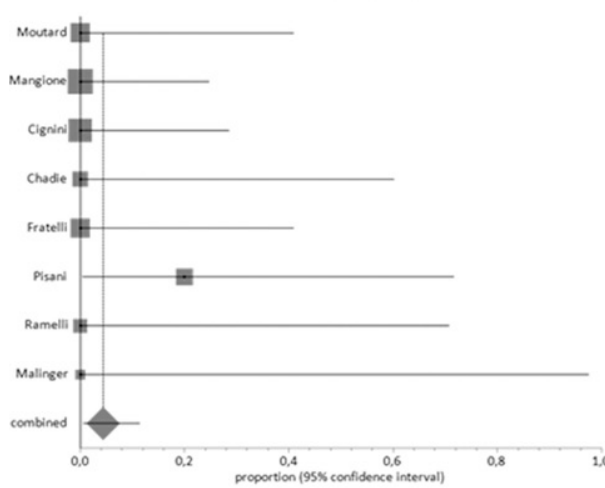

$0.00(0,00,0.41)$

$0.00(0,000,0.25)$

$0.00(0.00,0.28)$

$0.00(0,00,0.60)$

$0,00(0,00,0,41)$

$0.20(5,16-3,0.72)$

$0.00(0,00,0,71)$

$0.00(0,00,0.98)$

$0.04(6,26-3,0.11)$

Cognitive status

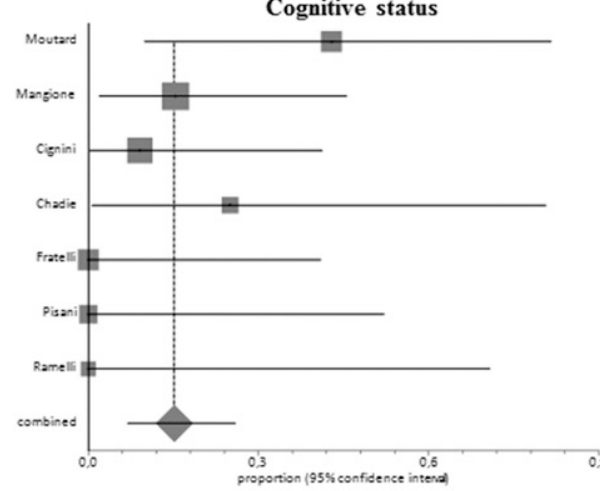

$0.43(0,10,0.82)$

$0.15(0,02,0,0,5)$

$0.09\{2,3 E-3,0.43\}$

$0.25(6,3 E-3,0.81)$

$0.00(0,00,0.49)$

$0.00\{0,00,052\}$

$0.00(0.00,078)$

$0.15(0.07,026$

'?

B

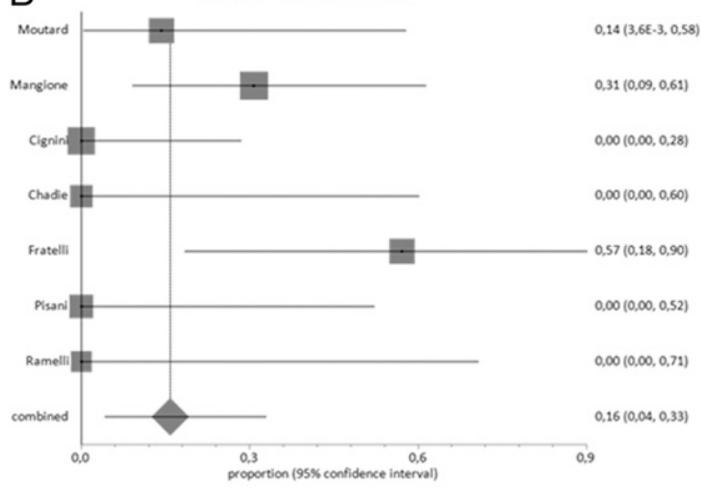

Language abnormalities

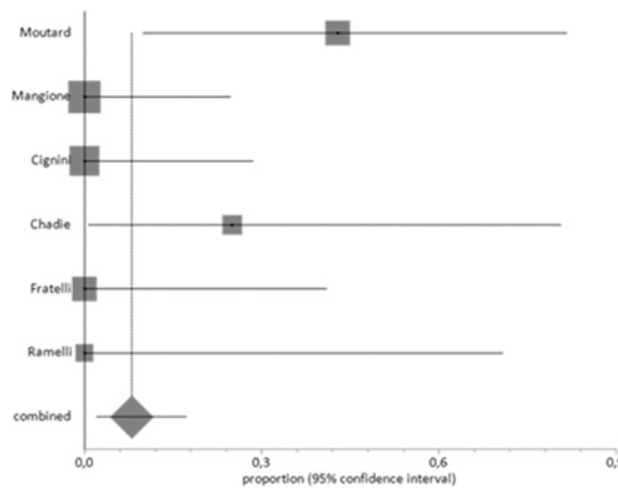

$0,00(0,00,0.71)$

0,9
Fine motor control

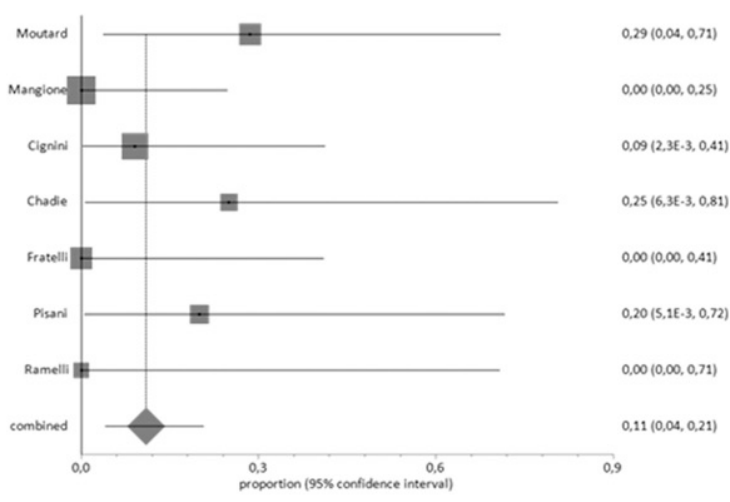

Epilepsy

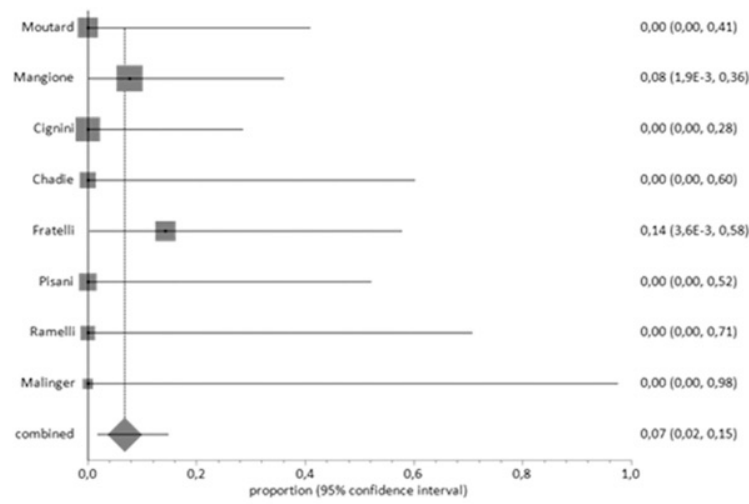

Abnormal sensory status

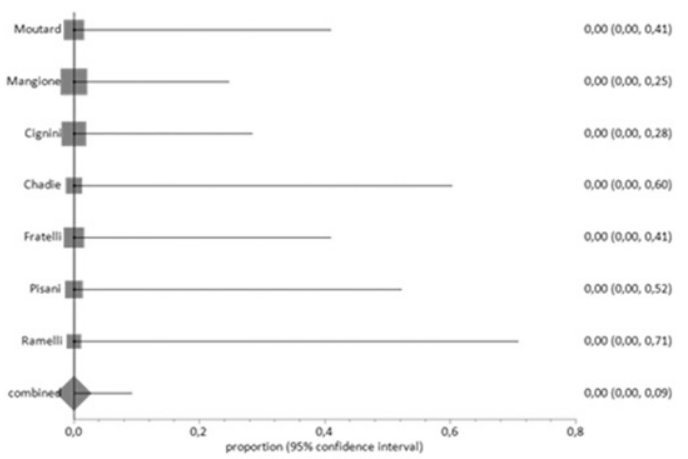

Abnormal coordination

$0.43(0.10,0.82)$

$0.00(0,00,0.25)$

$0.00(0,00,0,28)$

$0.25(6,36-3,0,82)$

$0,00(0,00,0,41)$

$0.08(0,02,0,17)$

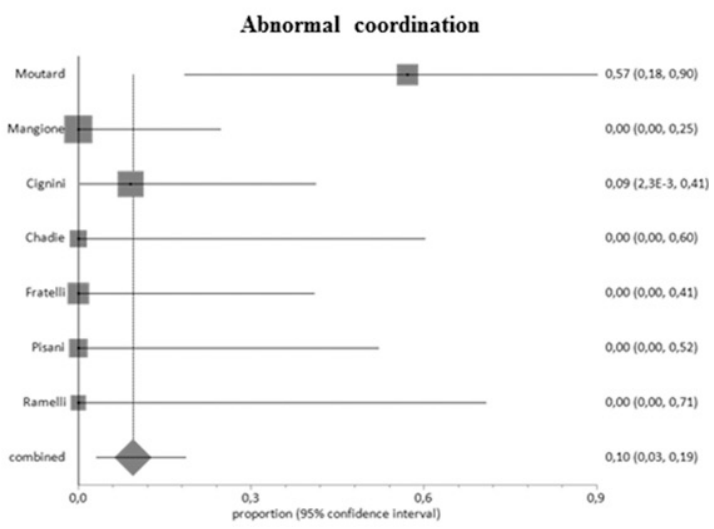

SUPPLEMENTAL FIGURE 8 A AND B,

Pooled proportions for the detailed neurodevelopmental outcome in children with a prenatal diagnosis of isolated cACC. 

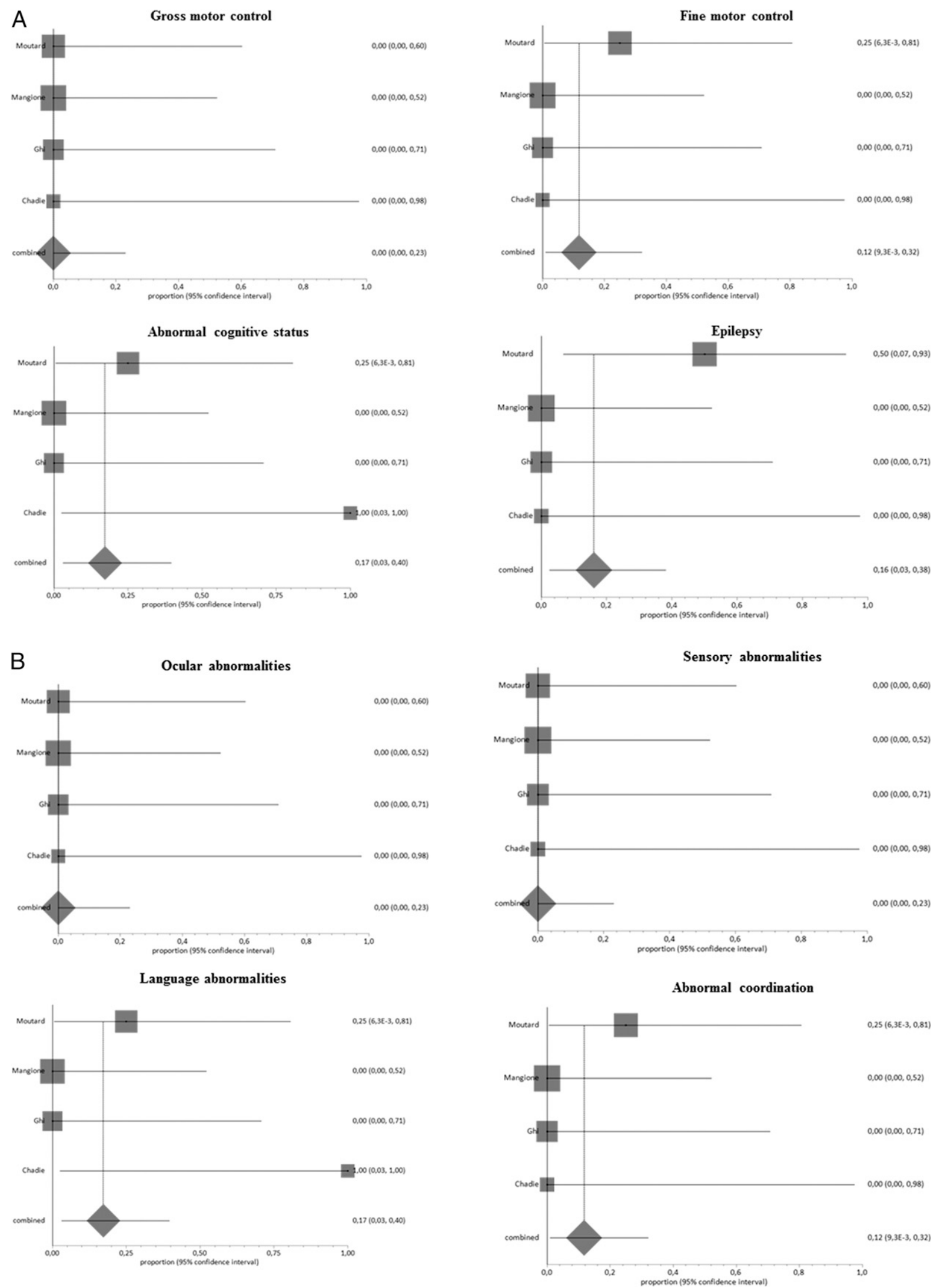

SUPPLEMENTAL FIGURE 9 A AND B,

Pooled proportions for the detailed neurodevelopmental outcome in children with a prenatal diagnosis of isolated pACC. 


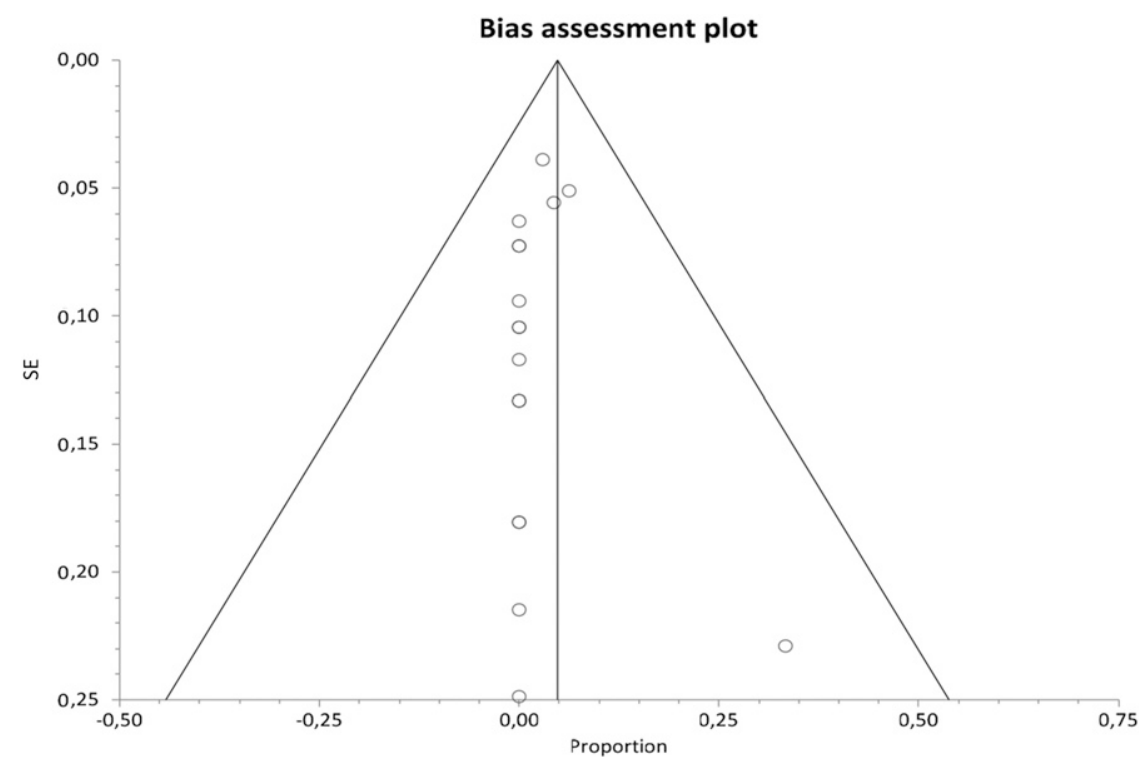

\section{SUPPLEMENTAL FIGURE 10}

Chromosomal anomalies. Bias indicators: Begg-Mazumdar: Kendall's $\tau \mathrm{b}=0.378788 ; P=.0421$. Egger: bias $=-0.076492(95 \% \mathrm{Cl}=-0.572401-0.419418) ; P=.7469$. Harbord: bias $=-0.153777(92.5 \%$ $\mathrm{Cl}=-0.965791-0658238) ; P=.7222$.

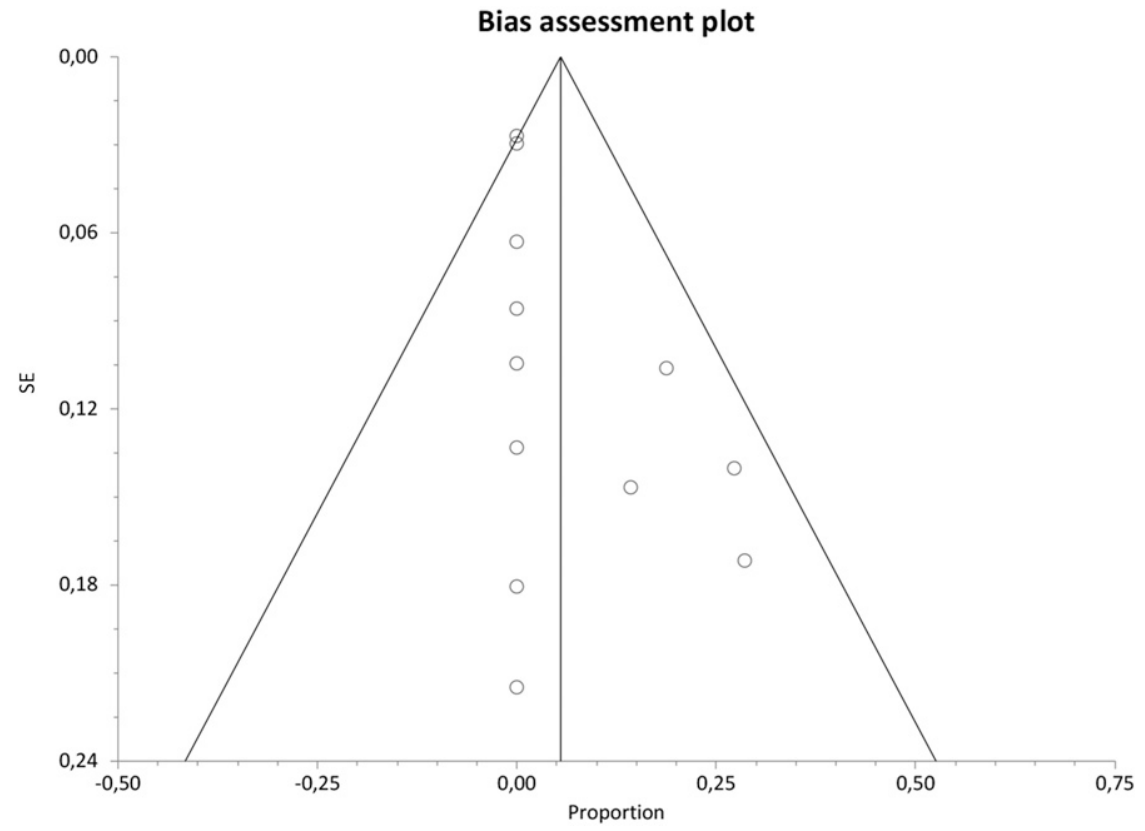

\section{SUPPLEMENTAL FIGURE 11}

Additional anomalies detected only postnatally. Bias indicators: Begg-Mazumdar: Kendall's $\tau=$ $0.606061 ; P=.0054$. Egger: bias $=0.870567(95 \% \mathrm{Cl}=0.060218-1.680917) ; P=.0377$. Harbord: bias $=$ $0.975389(92.5 \% \mathrm{Cl}=-1.603567-3.554345) ; P=.4697$. 


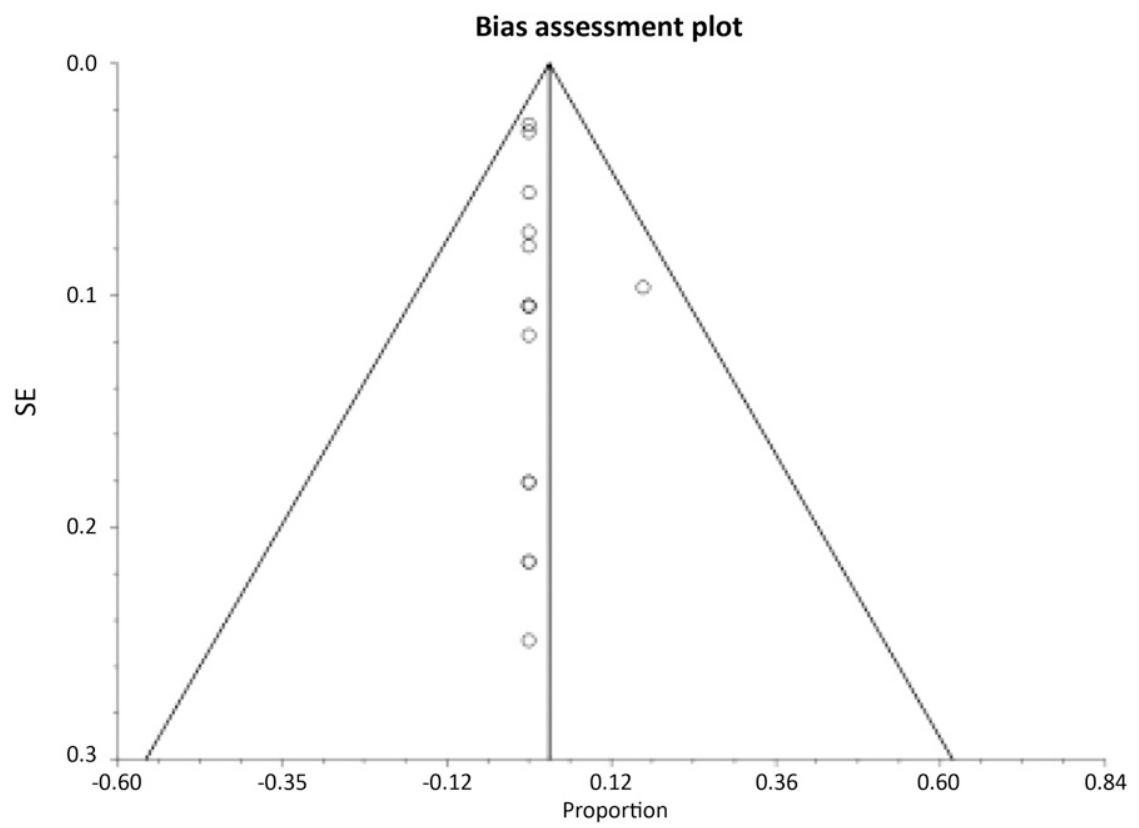

\section{SUPPLEMENTAL FIGURE 12}

Discrepancy between prenatal and postnatal diagnosis. Bias indicators: Begg-Mazumdar: Kendall's $\tau \mathrm{b}=0.828283 ; P<.0001$. Egger: bias $=0.147353(95 \% \mathrm{Cl}=-0.267738-0.562445) ; P=.4568$. Harbord: bias $=-0.272404(92.5 \% \mathrm{Cl}=-1511291-0966483) ; P=.6774$.

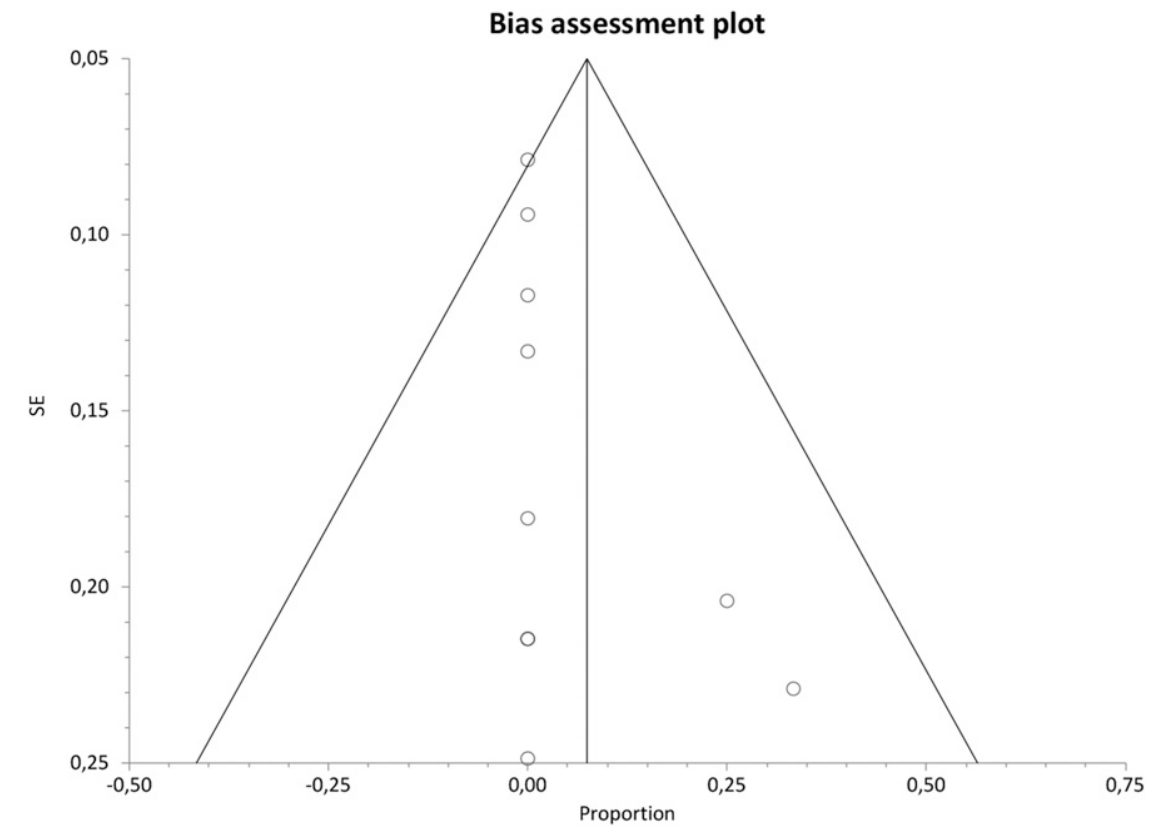

\section{SUPPLEMENTAL FIGURE 13}

Chromosomal anomalies. Bias indicators: Begg-Mazumdar: Kendall's $\tau b=0.857143 ; P=.0006$. Egger: bias $=0.571594(95 \% \mathrm{Cl}=-0.295155-1.438344) ; P=.1725$. Harbord: bias $=0.414035(92.5 \% \mathrm{Cl}$ $=-1.126938-1.955007) ; P=.6051$. 


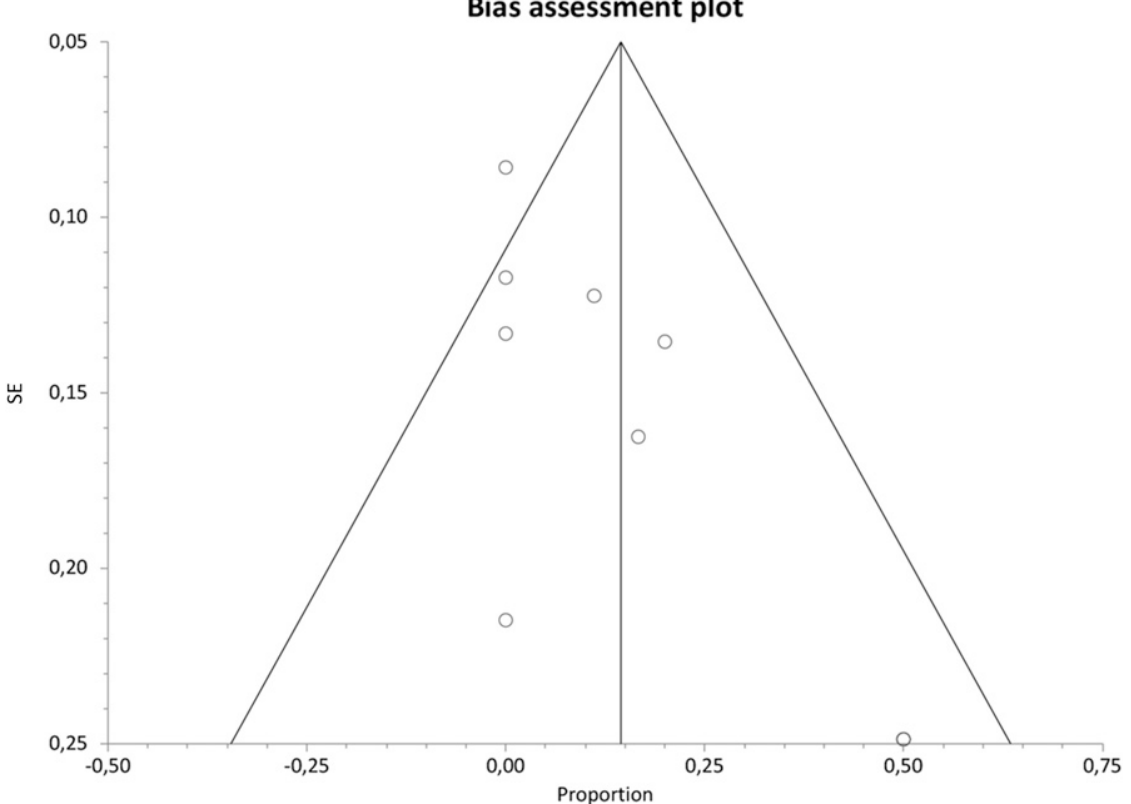

\section{SUPPLEMENTAL FIGURE 14}

Additional anomalies detected only postnatally. Bias indicators: Begg-Mazumdar: Kendall's $\tau$ b $=0.780488 ; P=.004$ (low power). Egger: bias $=2.512197(95 \% \mathrm{Cl}=0.985158-4039235) P=.0053$. Harbord: bias $=1.869821(92.5 \% \mathrm{Cl}=-0135642-3875284) ; P=.0929$. 


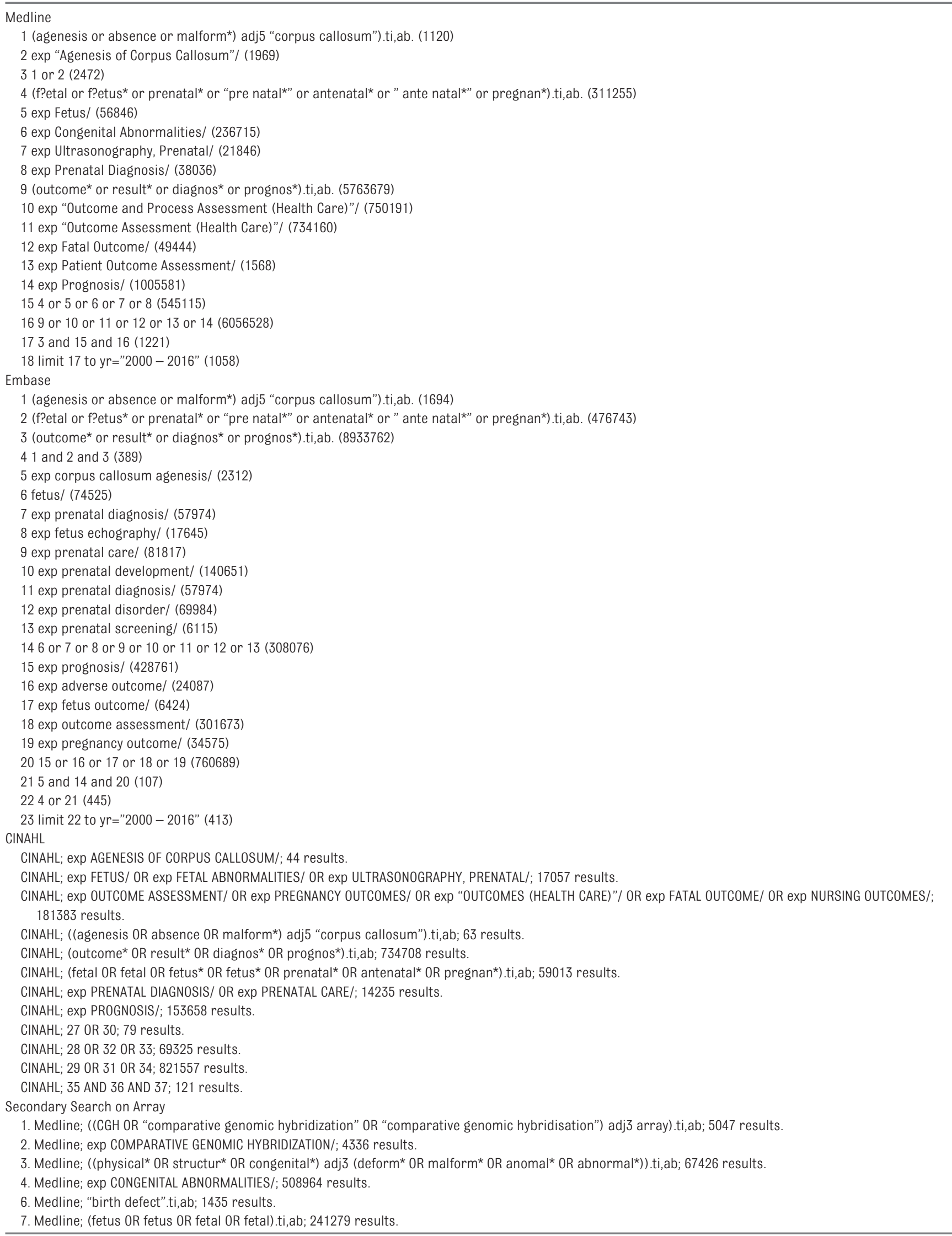


TABLE 5 Continued

8. Medline; exp FETUS/; 139476 results

9. Medline; 1 OR 2; 7367 results.

10. Medline; 3 OR 4 OR 6; 548514 results.

11. Medline; 7 OR $8 ; 314029$ results.

12. Medline; 9 AND 10 AND 11; 203 results.

13. Embase; ((CGH OR "comparative genomic hybridization" OR "comparative genomic hybridisation") adj3 array).ti,ab; 8268 results.

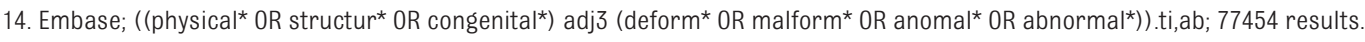

15. Embase; "birth defect".ti,ab; 1832 results.

16. Embase; (fetus $0 R$ fetus $0 R$ fetal $O R$ fetal).ti,ab; 283041 results.

17. Embase; exp COMPARATIVE GENOMIC HYBRIDIZATION/; 14239 results.

18. Embase; exp CONGENITAL DISORDER/; 870308 results.

19. Embase; exp FETUS/; 155614 results.

20. Embase; 13 OR 17; 16730 results.

21. Embase; 14 OR 15 OR 18; 900290 results.

22. Embase; 16 OR 19; 339130 results.

23. Embase; 20 AND 21 AND 22; 491 results.

24. CINAHL; ((CGH OR "comparative genomic hybridization" OR “comparative genomic hybridisation") adj3 array).ti,ab; 130 results.

25. CINAHL; ((physical* OR structur* OR congenital*) adj3 (deform* OR malform OR anomal* OR abnormal*)).ti,ab; 4075 results.

26. CINAHL; "birth defect".ti,ab; 165 results.

27. CINAHL; (fetus $O R$ fetus $0 R$ fetal $O R$ fetal).ti,ab; 14560 results.

29. CINAHL; $\operatorname{exp~ABNORMALITIES/;~} 35583$ results.

30. CINAHL; $\operatorname{exp~FETAL~ABNORMALITIES/;~} 398$ results.

31. CINAHL; exp FETUS/; 15547 results.

32. CINAHL; 25 OR 26 OR 29 OR 30; 38332 results.

33. CINAHL; 27 OR 31; 25119 results.

34. CINAHL; 24 AND 32 AND 33; 10 results. 
SUPPLEMENTAL TABLE 6 Excluded Studies and Reason for the Exclusion

\begin{tabular}{|c|c|c|}
\hline Author & Year & Reason for Exclusion \\
\hline Bell (1) & 2015 & It was not possible to extrapolate data for CACC and pACC separately. Authors contacted, no reply. \\
\hline Craven (2) & 2015 & $\begin{array}{l}\text { Study assessing the predictive accuracy of fetal MRI in detecting callosal anomalies. It was not specified how isolated ACC was defined } \\
\text { and there was not differentiation between agenesis and hypogenesis of the CC, thus it was not possible to extrapolate data for any } \\
\text { of the outcomes explored in this systematic review }\end{array}$ \\
\hline Jakab (3) & 2015 & Cases included in these series are shared with the paper by Kasprian et al ${ }^{24}$. \\
\hline Contro (4) & 2015 & $\begin{array}{l}\text { No data for the outcomes observed in this systematic review. Part of the population is shared with the paper of Cesaretti et al }{ }^{17} \\
\text { included in the current review. }\end{array}$ \\
\hline Wiechec (5) & 2015 & $\begin{array}{l}\text { No data for the outcomes explored in this systematic review could be extrapolated from this series. Authors contacted, no information } \\
\text { available. }\end{array}$ \\
\hline
\end{tabular}

Srebniak (6)

2015 The authors reported that 2 cases of ACC had additional abnormal findings at array; however, it was not possible to extrapolate the

Sun (7)

Van Opstal (8)

Yakut (9)

Ballardini (10)

Lightly (11)

Tugcu (12)

Zamurović (13)

Tonni (14)

Noguchi (15)

overall number of isolated ACC and norn

2015 No data for the outcomes explored in this systematic review could be extrapolated from this study.

2015 No case of isolated ACC included in this series.

2014 Only 1 case of ACC diagnosed before birth included in this study.

2014 Conference abstract.

2014 Only 1 fetus with ACC with other anomalies included in this series; no other data for the outcomes explored in this systematic review.

2014 Case report.

2014 No data for the outcomes explored in this review could be extrapolated from this study. Author contacted no reply.

Amer (16)

Brady (17)

Carey (18)

Kan (19)

Adle-Biassette

(20)

Floridia (21)

2014

All cases included in this series had ventriculomegaly $<15 \mathrm{~mm}$, which is an exclusion criteria for this review. Author contacted, no reply

2014 No data for the outcomes explored in this systematic review could be extrapolated from this study. Author contacted, no reply.

2014 No data on array abnormalities in fetuses with isolated ACC could be extrapolated from this study. Authors contacted no reply.

2014 No data on array abnormalities in fetuses with isolated ACC could be extrapolated from this study. Authors contacted no reply.

2014 No data on array abnormalities in fetuses with isolated ACC could be extrapolated from this study. Authors contacted, no reply.

2013 Autopsy-based study; no data for the outcomes observed in this systematic review.

Garcia-Flores

2013 Only cases exposed to antiretroviral therapy included in this series. <3 cases of fetuses with ACC included. No data for the outcomes explored in this review.

(22)

Hamisa (23)

Hergan (24)

Huang (25)

Paladini (26)

Evangelidou (27)

2013

$<3$ cases of ACC included in this series; furthermore, the only cases of pACC included was not confirmed at prenatal imaging.

2013 Only 2 cases of ACC associated with other anomalies were included in this series.

2013 Case report.

2013 No data for the outcomes observed in this systematic review could be extrapolated from this series.

2013 No data for the outcome explored in this systematic review could be extrapolated from this study.

Ganesamoorthy

(28)

Hillman (29)

Rooryck (30)

Schmid (31)

No data on the overall num

2013 No data on the overall number of fetuses with isolated ACC and normal karyotype could be extrapolated from this series. Authors contacted, no reply.

2013 No data on the overall number of fetuses with isolated ACC and normal karyotype could be extrapolated from this series. Authors contacted, no reply.

2013 No data on the overall number of fetuses with isolated ACC and normal karyotype could be extrapolated from this series. Authors contacted, no reply.

2013 No data on the overall number of fetuses with isolated ACC and normal karyotype could be extrapolated from this series. Authors contacted, no reply.

Scott (32)

Srebniak (33)

2013 Only 1 case of isolated ACC included in this series.

Dill (34)

2013 No data on the overall number of fetuses with isolated ACC and normal karyotype could be extrapolated from this series. Authors contacted, no reply.

2012 Study assessing the predictive accuracy of fetal MRI in detecting callosal anomalies. It was not specified how isolated ACC was defined and there was not differentiation between agenesis and hypogenesis of the ML, thus it was not possible to extrapolate data for any of the outcomes explored in this systematic review. Authors contacted, no additional data available.

Kameda (35)

Malinger (36)

Oh (37)

Li (38)

Putoux (39)

We (40)

No data for the outcomes explored in this review.

2012 No data for the outcomes explored in this review.

2012 No data for the outcomes observed in this systematic review. The study deals with ACC associated with severe ventriculomegaly and interhemispheric cyst, which is an exclusion criteria for this systematic review.

2012 It was not possible to extrapolate data for CACC and PACC separately. Furthermore, it was not clear whether associated extracranial anomalies were present in cases with isolated ACC. Authors contacted, no reply.

Yamasaki (41)

Only 1 fetus with ACC with other anomalies included in this series; no other data for the outcomes explored in this systematic review.

2012 No data for the outcomes observed in this systematic review could be extrapolated from this series.

2012 No data for the outcomes observed in this systematic review could be extrapolated from this series. 
TABLE 6 Continued

\begin{tabular}{|c|c|c|}
\hline Author & Year & Reason for Exclusion \\
\hline Griffiths (42) & 2012 & $\begin{array}{l}\text { Study assessing the predictive accuracy of fetal MRI in brain anomalies. It was not clear whether those cases having ACC were isolated } \\
\text { or not and no other information on the outcomes explored in this systematic review could be extrapolated from this study. Authors } \\
\text { contacted, no reply. }\end{array}$ \\
\hline Breman (44) & 2012 & No data on array abnormalities in fetuses with isolated ACC could be extrapolated from this study. Authors contacted, no reply. \\
\hline Bruno (45) & 2012 & $\begin{array}{l}\text { No data on the overall number of fetuses with isolated ACC and normal karyotype could be extrapolated from this series. Authors } \\
\text { contacted, no reply. }\end{array}$ \\
\hline Gruchy (48) & 2012 & $\begin{array}{l}\text { No data on the overall number of fetuses with isolated ACC and normal karyotype could be extrapolated from this series. Authors } \\
\text { contacted, no reply. }\end{array}$ \\
\hline Hillman (49) & 2012 & Review article, no original data reported. \\
\hline Novelli (50) & 2012 & Review article, no original data reported. \\
\hline Yatsenko (51) & 2012 & $\begin{array}{l}\text { No data on the overall number of fetuses with isolated ACC and normal karyotype could be extrapolated from this series. Authors } \\
\text { contacted, no reply. }\end{array}$ \\
\hline Haratz (54) & 2011 & No data for the outcomes explored in this review. \\
\hline Ozkan (55) & 2011 & Only 1 case of ACC included in this study. \\
\hline Rouleau (56) & 2011 & No data for the outcomes explored in this review could be extrapolated from this study. \\
\hline Rizzo (57) & 2011 & No data for the outcomes explored in this systematic review could be extrapolated from this study. \\
\hline Fiorentino (58) & 2011 & No data on array abnormalities in fetuses with isolated ACC could be extrapolated from this study. Authors contacted, no reply. \\
\hline Leung (59) & 2011 & Only fetuses with increased NT included in this series; furthermore, no case of isolated ACC was included. \\
\hline Park (60) & 2011 & $\begin{array}{l}\text { No data on the overall number of fetuses with isolated ACC and normal karyotype could be extrapolated from this series. Authors } \\
\text { contacted, no reply. }\end{array}$ \\
\hline Srebniak (61) & 2011 & No case of isolated ACC included in this series. Authors contacted, no reply. \\
\hline Di Bella (62) & 2010 & Only cases presenting with symptoms and diagnosed postnatally included in this study. \\
\hline $\begin{array}{l}\text { Dommergues } \\
\text { (63) }\end{array}$ & 2010 & No data for the outcomes explored in this review. \\
\hline
\end{tabular}

Warren (70)

2010 No data for the outcomes explored in this systematic review could be extrapolated from this study. Authors contacted, no reply.

Evangelidou (71) $2010 \quad$ No case of isolated ACC included in this series.

Maya (72)

Blaas (73)

Lerman-Sagie

2010 No data on array abnormalities in fetuses with isolated ACC could be extrapolated from this study.

2009 Narrative review; no original data provided.

(74)

Tang (75)

Coppinger (76)

Kleeman (77)

Tyreman (78)

Van den Veyver

Vialard (80)

Callen (81)

2009

No data for the outcomes explored in this review.

2009 It was not to possible to extrapolate individual data for CACC and pACC. Author contacted, no information available.

$2009<3$ cases of ACC included in this series.

2009 No case of isolated ACC and normal karyotype included in this study

2009 No data on array abnormalities in fetuses with isolated ACC could be extrapolated from this study. Authors contacted, no reply.

2009 No data on array abnormalities in fetuses with isolated ACC could be extrapolated from this study.

2009 Only pregnancies referred to termination included in this study.

2008 No data for the outcomes explored in this review; only 1 case of ACC included.
Hagmann (82)
2008 Study assessing the predictive accuracy of fetal MRI in detecting callosal anomalies. It was not specified how isolated ACC was defined and there was no differentiation between agenesis and hypogenesis of the ML, thus it was not possible to extrapolate data for any of the outcomes explored in this systematic review. Authors contacted, no additional data available.

Hadzagić- $\quad 2008$ Only 2 cases of ACC detected before birth included in this series

Catibusić (83)

Bi (84)

2008 No data on array abnormalities in fetuses with isolated ACC included in this study. 
TABLE 6 Continued

\begin{tabular}{|c|c|c|}
\hline Author & Year & Reason for Exclusion \\
\hline Benacerraf (85) & 2007 & $\begin{array}{l}\text { Study assessing the predictive accuracy of fetal MRI in detecting callosal anomalies. It was not specified how isolated ACC was defined } \\
\text { and there was no differentiation between agenesis and hypogenesis of the ML, thus it was not possible to extrapolate data for any of } \\
\text { the outcomes explored in this systematic review. Authors contacted, no additional data available. }\end{array}$ \\
\hline Breeze (86) & 2007 & No data for the outcomes explored in this review. \\
\hline Moritake (87) & 2007 & No data for the outcomes explored in this systematic review could be extrapolated from this study. \\
\hline Sohn (88) & 2007 & $\begin{array}{l}\text { Study assessing the predictive accuracy of fetal MRI in detecting callosal anomalies. It was not specified how isolated ACC was defined } \\
\text { and there was no differentiation between agenesis and hypogenesis of the ML, thus it was not possible to extrapolate data for any of } \\
\text { the outcomes explored in this systematic review. }\end{array}$ \\
\hline De Gregori (89) & 2007 & No data on array abnormalities in fetuses with isolated ACC included in this study. \\
\hline Gullotta (90) & 2007 & No case of isolated ACC included in this series. \\
\hline Lee $(91)$ & 2006 & Only 2 cases of ACC diagnosed prenatally included in this series. \\
\hline Sacco $(92)$ & 2006 & $\begin{array}{l}\text { No data for the outcomes observed in this systematic review. Part of the population of this paper is present in another study included } \\
\text { in the review (Moutard et } \mathrm{al}^{31} \text { ) }\end{array}$ \\
\hline Rickard (93) & 2006 & $\begin{array}{l}\text { Study assessing the predictive accuracy of fetal MRI in brain anomalies. It was not clear whether those cases having ACC had normal } \\
\text { karyotype and no other information on the outcomes explored in this systematic review could be extrapolated from this study. } \\
\text { Authors contacted, no reply }\end{array}$ \\
\hline Miura (94) & 2006 & $\begin{array}{l}\text { No data on the overall number of fetuses with isolated ACC and normal karyotype could be extrapolated from this series. Authors } \\
\text { contacted, no reply. }\end{array}$ \\
\hline Sahoo (95) & 2006 & No data on array abnormalities in fetuses with isolated ACC could be extrapolated from this study. \\
\hline Belhocine (96) & 2005 & No data for the outcomes explored in this systematic review. \\
\hline Blaicher (97) & 2005 & $\begin{array}{l}\text { Study assessing the predictive accuracy of fetal MRI in detecting callosal anomalies. It was not specified how isolated ACC was defined } \\
\text { and there was no differentiation between agenesis and hypogenesis of the ML, thus it was not possible to extrapolate data for any } \\
\text { of the outcomes explored in this systematic review. Furthermore, another study from the same group was included and considered } \\
\text { more representative. }\end{array}$ \\
\hline Breeze (98) & 2005 & No data for the outcomes explored in this review; authors contacted, no reply \\
\hline Brown (99) & 2005 & Only cases diagnosed postnatally included in this study. \\
\hline Leung (100) & 2005 & No data for the outcomes explored in this review. \\
\hline D’Addario (101) & 2005 & No data for the outcomes explored in this systematic review could be extrapolated from this study. \\
\hline Le Caignec (102) & 2005 & $\begin{array}{l}\text { Only fetuses with at least } \geq 3 \text { structural anomalies included in this series. Furthermore, this study included only pregnancies } \\
\text { terminated or that ended in spontaneous fetal death. }\end{array}$ \\
\hline Rickman (103) & 2005 & No data on array abnormalities in fetuses with isolated ACC could be extrapolated from this study. Authors contacted, no reply. \\
\hline Frates (104) & 2004 & Only 1 case of ACC included in this study. \\
\hline Guillem (105) & 2004 & The study includes exclusively pregnancy terminations, which is an exclusion criteria for this systematic review. \\
\hline Malinger (106) & 2004 & $\begin{array}{l}\text { Study assessing the predictive accuracy of fetal MRI in brain anomalies. It was not clear whether those cases having ACC were isolated } \\
\text { or not and no other information on the outcomes explored in this systematic review could be extrapolated from this study. }\end{array}$ \\
\hline Whitby (107) & 2004 & $\begin{array}{l}\text { Study assessing the predictive accuracy of fetal MRI in detecting callosal anomalies. It was not specified how isolated ACC was defined } \\
\text { and there was not differentiation between agenesis and hypogenesis of the ML, thus it was not possible to extrapolate data for any } \\
\text { of the outcomes explored in this systematic review. Authors contacted, no reply. }\end{array}$ \\
\hline Wald (108) & 2004 & No data for the outcomes explored in this systematic review could be extrapolated from this study. Authors contacted, no reply. \\
\hline Larrabee (109) & 2004 & No case of isolated ACC included in this series. Authors contacted, no reply. \\
\hline Twickler (110) & 2003 & No data for the outcomes explored in this systematic review could be extrapolated from this study. Authors contacted, no reply. \\
\hline Bekker (111) & 2001 & Review article, no original data included. \\
\hline Whitby (112) & 2001 & $\begin{array}{l}\text { Study assessing the predictive accuracy of fetal MRI in detecting callosal anomalies. It was not specified how isolated ACC was defined } \\
\text { and there was no differentiation between agenesis and hypogenesis of the ML, thus it was not possible to extrapolate data for any of } \\
\text { the outcomes explored in this systematic review. Authors contacted, no reply. }\end{array}$ \\
\hline Greco (113) & 2001 & It was not possible to extrapolate individual data for complete and partial ACC. Author contacted, no reply. \\
\hline Ickowitz (114) & 2000 & $\begin{array}{l}\text { The study deals with prenatal diagnosis of pericallosal lipoma. No data for the outcomes observed in this systematic review could be } \\
\text { extrapolated from this study }\end{array}$ \\
\hline Marszał (115) & 2000 & Postnatal series of children with ACC. \\
\hline
\end{tabular}


SUPPLEMENTAL TABLE 7 Chromosomal Anomalies in Fetuses With Isolated cACC

\begin{tabular}{|c|c|c|c|c|c|}
\hline & No. of Studies $(n)$ & Fetuses $(n / M)$ & $I^{2}(\%)$ & Raw \% (95\% Cl) & Pooled \% (95\% Cl) \\
\hline Trisomy 21 & 17 & $1 / 174$ & 0 & $0.57(0.1-3.2)$ & $2.45(0.7-5.2)$ \\
\hline Trisomy 18 & 17 & $0 / 174$ & 0 & $0(0.1-2.1)$ & $0(0-2.1)$ \\
\hline Trisomy 13 & 17 & $1 / 174$ & 0 & $0.57(0.1-3.2)$ & $2.11(0.5-4.7)$ \\
\hline Triploidy & 17 & $0 / 174$ & 0 & $0(0-2.1)$ & $0(0-2.1)$ \\
\hline Deletions & 17 & $1 / 174$ & 0 & $0.57(0.1-3.2)$ & $2.57(0.8-5.4)$ \\
\hline Inversions & 17 & $0 / 174$ & 0 & $0(0-2.1)$ & $0(0-2.1)$ \\
\hline Duplications & 17 & $0 / 174$ & 0 & $0(0-2.1)$ & $0(0-2.1)$ \\
\hline Others & 17 & $2 / 174$ & 0 & $1.15(0.1-4.1)$ & $2.93(1.0-5.8)$ \\
\hline
\end{tabular}

SUPPLEMENTAL TABLE 8 Individual Case Description of Associated Anomalies Detected Only at Fetal MRI in Fetuses With Isolated cACC

\begin{tabular}{lcccc}
\hline Author & Year & Isolated ACC $(n)$ & $\begin{array}{c}\text { Additional Anomalies } \\
\text { Detected Only at Fetal MRI }\end{array}$ & Type of Anomaly \\
\hline Kasprian (28) & 2013 & 11 & 2 & $\begin{array}{c}\text { Case 1: subependymal heterotopia, hypoplastic } \\
\text { cerebellum } \\
\text { Case 2: metabolic disorder (not specified) } \\
\text { Case 1: abnormal pons Case 2: abnormal sulcation } \\
\text { morphology, dysplastic ventricles, abnormal } \\
\text { multilayered pattern }\end{array}$ \\
Tang (38) & 2009 & 7 & 2 & Abnormal position of the hyppocampus \\
\hline
\end{tabular}

SUPPLEMENTAL TABLE 9 Individual Case Description of Associated Anomalies Detected Only After Birth in Children with a Prenatal Diagnosis of Isolated CACC

\begin{tabular}{|c|c|c|c|c|}
\hline Author & Year & Isolated ACC (n) & $\begin{array}{l}\text { Additional Anomalies Detected Only } \\
\text { Postnatally }\end{array}$ & Type of Anomaly \\
\hline Mangione (35) & 2011 & 16 & 3 & $\begin{array}{l}1 \text { congenital torticollis, } 1 \text { congenital torticollis and hydrocephaly, } 1 \\
\text { Peter syndrome }\end{array}$ \\
\hline Chadie (40) & 2008 & 11 & 3 & 1 cortical heterotopia, 1 MCM, 1 hexadactyly of the feet \\
\hline Pisani (42) & 2006 & 7 & 2 & $\begin{array}{l}\text { 1: cerebellar caudal vermis hypoplasia, cerebellar posterior lobes } \\
\text { hypoplasia 2: macroglossia, hypertelorism, low-set ear }\end{array}$ \\
\hline Moutard (31) & 2003 & 7 & 1 & Fetal alchool syndrome \\
\hline
\end{tabular}

SUPPLEMENTAL TABLE 10 Detailed Individual Outcome of Children With Isolated cACC

\begin{tabular}{|c|c|c|c|c|}
\hline Author & Year & Case $(n)$ & Prenatal Information & Outcome Description \\
\hline \multirow{9}{*}{$\begin{array}{l}\text { Mangione } \\
\text { (35) }\end{array}$} & 2011 & & & \\
\hline & & 1 & Born at term & DQ-CDI: 112; convulsions; age at assessment: 59 mo \\
\hline & & 2 & Born at term & Borderline development; DQ-CDI: 77; age at assessment: 48 mo \\
\hline & & 3 & Born at term & Squinting, DQ-CDI: 97; age at assessment: 50 mo \\
\hline & & 4 & Born at term & Squinting, DQ-CDI: 89; age at assessment: 33 mo \\
\hline & & 5 & Born at term & Squinting, DQ-CDI: 104; age at assessment: 55 mo \\
\hline & & 6 & Born at term & Squinting, DQ-CDI: 95; age at assessment: 39 mo \\
\hline & & 7 & Born at term & Retarded; DQ-CDI: 47; age at assessment: 32 mo \\
\hline & & 8 & Born at term & Retarded; age at assessment: 60 mo \\
\hline \multirow[t]{2}{*}{ Cignini (37) } & 2010 & & & \\
\hline & & 1 & Born at term & Mild hypotonia, coordination deficit; IQ: 70 \\
\hline \multirow[t]{3}{*}{ Chadie (40) } & 2008 & & & \\
\hline & & 1 & Born at term & Moderate retardation in language; speech therapy. Head circumference -1 SD \\
\hline & & 2 & Born at term & $\begin{array}{l}\text { Normal at } 2 \text { y but at } 8 \text { y cannot read or write, delayed cognitive acquisitions; WISC III at 7y: total } \\
\text { IQ } 59 \text { (performance IQ 66; verbal IQ 62); special education, psychotherapy, speech therapy. } \\
\text { Head circumference-1 SD. }\end{array}$ \\
\hline \multirow[t]{3}{*}{ Pisani (42) } & 2006 & & & \\
\hline & & 1 & Born preterm (34 wk) & $\begin{array}{l}\text { Generalized hypotonia, asymmetry of the electrical activity at EEG, followed by the appearance } \\
\text { of the focus without clinical correlations }\end{array}$ \\
\hline & & 2 & Born at term & Mild generalized hypotonia \\
\hline
\end{tabular}


SUPPLEMENTAL TABLE 11 Chromosomal Anomalies in Fetuses With Isolated pACC

\begin{tabular}{|c|c|c|c|c|c|}
\hline & No. of Studies $(n)$ & Fetuses $(n / M)$ & $\mathrm{I}^{2}(\%)$ & Raw \% (95\% Cl) & Pooled \% (95\% Cl) \\
\hline Trisomy 21 & 12 & $0 / 48$ & 0 & $0(0-7.4)$ & $0(0-7.4)$ \\
\hline Trisomy 18 & 12 & $1 / 48$ & 0 & $2.08(0.1-11.1)$ & $6.17(1.4-14.1)$ \\
\hline Trisomy 13 & 12 & $0 / 48$ & 0 & $0(0-7.4)$ & $0(0-7.4)$ \\
\hline Triploidy & 12 & $0 / 48$ & 0 & $0(0-7.4)$ & $0(0-7.4)$ \\
\hline Deletions & 12 & $1 / 48$ & 0 & $2.08(0.1-11.1)$ & $6.02(1.3-13.8)$ \\
\hline Inversions & 12 & $0 / 48$ & 0 & $0(0-7.4)$ & $0(0-7.4)$ \\
\hline Duplications & 12 & $0 / 48$ & 0 & $0(0-7.4)$ & $0(0-7.4)$ \\
\hline Others & 12 & $0 / 48$ & 0 & $0(0-7.4)$ & $0(0-7.4)$ \\
\hline
\end{tabular}

SUPPLEMENTAL TABLE 12 Individual Case Description of Associated Anomalies Detected Only at Fetal MRI in Fetuses With Isolated pACC

\begin{tabular}{lcccl}
\hline Author & Year & Isolated ACC $(n)$ & $\begin{array}{c}\text { Additional Anomalies Detected Only at } \\
\text { Prenatal MRI }\end{array}$ & Type of Anomaly \\
\hline Yinon (29) & 2013 & 2 & 2 & $\begin{array}{l}\text { Case 1: periventricular heterotopia } \\
\text { Case 2: septo-optic dysplasia } \\
\text { Retardation of cortical folding }\end{array}$ \\
\hline
\end{tabular}

SUPPLEMENTAL TABLE 13 Individual Case Description of Associated Anomalies Detected Only After Birth in Children With a Prenatal Diagnosis of Isolated PACC

\begin{tabular}{|c|c|c|c|c|}
\hline Author & Year & Isolated ACC $(n)$ & Additional Anomalies Detected Only Postnatally & Type of Anomaly \\
\hline Pashaj (25) & 2015 & 2 & 1 & $\begin{array}{l}\text { Asymmetric face due to hypoplasia of } \mathrm{m} \text {. depressor } \\
\text { anguli oris left }\end{array}$ \\
\hline Mangione (35) & 2011 & 6 & 1 & Non-ketotic hyperglycemia \\
\hline Ghi (36) & 2010 & 10 & 2 & $\begin{array}{l}\text { Case 1: Multiple intra-cranial lipomas Case 2: } \\
\text { CHARGE syndrome }\end{array}$ \\
\hline Chadie (40) & 2008 & 2 & 1 & $\begin{array}{l}\text { Hypoplasia, cortical atrophy, choroid plexus cysts, } \\
\text { dysmorphia, hypospadias }\end{array}$ \\
\hline Volpe (44) & 2006 & 9 & 1 & Nodular peri-ventricular heterotopia \\
\hline Blaicher (45) & 2003 & 2 & 1 & Cranial dysmorphia \\
\hline
\end{tabular}

SUPPLEMENTAL TABLE 14 Detailed Individual Outcome of Children With Isolated pACC

\begin{tabular}{lccll}
\hline Author & Year & Case $(\mathrm{n})$ & Prenatal Information & \\
\hline Mangione (35) & 2011 & & Outcome Description \\
Ghi (36) & 2010 & 1 & Born at term & Borderline development; DQ-CDI: 76; difficulty in swallowing; age at assessment: 47 mo \\
Chadie (40) & 2008 & 1 & Born at term & Epilepsy \\
& 1 & Born at term & $\begin{array}{l}\text { Transient disabilities: WPPSI-III at 3y 10mo: performance IQ 100, verbal IQ 83.Special education } \\
\text { initially, psychotherapy, speech therapy. Normal at the age of 5. Head circumference at birth: } \\
\text { average. }\end{array}$ \\
Volpe (44) & 2006 & & Born at term & $\begin{array}{l}\text { Severe delay; hypotonia and feeding difficulties } \\
\text { Severe delay (not otherwise specified) }\end{array}$ \\
\hline
\end{tabular}




\section{SUPPLEMENTAL REFERENCES}

1. Bell S, O'Mahony E, Fink AM, Woodrow N, Reidy K, Palma-Dias R. Antenatal imaging of anomalies of the corpus callosum: a decade of experience. Arch Gynecol Obstet. 2015;292(3):537-542

2. Craven I, Bradburn MJ, Griffiths PD. Antenatal diagnosis of agenesis of the corpus callosum. Clin Radiol. 2015;70(3):248-253

3. Jakab A, Kasprian G, Schwartz E, et al. Disrupted developmental organization of the structural connectome in fetuses with corpus callosum agenesis. Neuroimage. 2015;111:277-288

4. Contro E, Nanni M, Bellussi F, et al. The hippocampal commissure: a new finding at prenatal 3D ultrasound in fetuses with isolated complete agenesis of the corpus callosum. Prenat Diagn. 2015;35(9):919-922

5. Wiechec M, Nocun A, Knafel A, Beithon J, Stettner D. Four steps in diagnosing complete agenesis of the Corpus Callosum in prenatal life. Ultraschall in Med. 2016;37(1):92-99

6. Srebniak MI, Diderich KE, Joosten $\mathrm{M}$, et al. Prenatal SNP array testing in 1000 fetuses with ultrasound anomalies: causative, unexpected and susceptibility CNVs. Eur J Hum Genet. 2016;24(5):645-651

7. Sun L, Wu Q, Jiang SW, et al. Prenatal diagnosis of central nervous system anomalies by high resolution chromosomal microarray analysis. Biomed Res Int. 2015;2015:426379

8. Van Opstal D, de Vries F, Govaerts L, et al. Benefits and burdens of using a SNP array in pregnancies at increased risk for the common aneuploidies. Hum Mutat. 2015;36(3): 319-326

9. Yakut S, Çetin Z, Şİmşek M, et al. Rare structural chromosomal abnormalities in prenatal diagnosis; clinical and cytogenetic findings on 10125 prenatal cases. Turk Patoloji Derg. 2015;31(1):36-44

10. Ballardini E, Tarocco A, Baldan A, Antoniazzi E, Garani G, BorgnaPignatti C. Universal cranial ultrasound screening in preterm infants with gestational age 33-36 weeks. A retrospective analysis of 724 newborns. Pediatr Neurol. 2014;51(6):790-794

11. Lightly K, Simms R, Leibling R, Overton $T$, Denbow M. Magnetic Resonance Imaging (MRI) of the fetal brain improve accuracy of diagnosis for mild and severe ventriculomegaly. Arch Dis Child Fetal Neonatal Ed. 2014;99:A97

12. Tugcu AU, Gulumser C, Ecevit A, et al. Prenatal evaluation and postnatal early outcomes of fetal ventriculomegaly. Eur J Paediatr Neurol. 2014;18(6):736-740

13. Zamurović M, Andjelic S. Partial agenesis of corpus callosum-case study. Clin Exp Obstet Gynecol. 2014;41(2):233-235

14. Tonni G, Grisolia G, Sepulveda W. Second trimester fetal neurosonography: reconstructing cerebral midline anatomy and anomalies using a novel threedimensional ultrasound technique. Prenat Diagn. 2014;34(1):75-83

15. Noguchi R, Abe K, Hamada $\mathrm{H}$, et al. Outcomes of patients with prenatally diagnosed agenesis of the corpus callosum in conjunction with ventriculomegaly. Arch Gynecol Obstet 2014;290(2):237-242

16. Amer N, Amer M, Kolkailah M, AlDumairy M. Foetal central nervous system anomalies: frequency and foeto-maternal outcome. J Pak Med Assoc. 2014;64(11):1282-1286

17. Brady PD, Delle Chiaie B, Christenhusz $G$, et al. A prospective study of the clinical utility of prenatal chromosomal microarray analysis in fetuses with ultrasound abnormalities and an exploration of a framework for reporting unclassified variants and risk factors. Genet Med. 2014;16(6):469-476

18. Carey L, Scott F, Murphy K, et al. Prenatal diagnosis of chromosomal mosaicism in over 1600 cases using array comparative genomic hybridization as a first line test. Prenat Diagn. 2014;34(5):478-486
19. Kan AS, Lau ET, Tang WF, et al. Wholegenome array CGH evaluation for replacing prenatal karyotyping in Hong Kong. PLoS One. 2014;5(9):e87988

20. Adle-Biassette H, Saugier-

Veber P, Fallet-Bianco C, et al. Neuropathological review of 138 cases genetically tested for $X$-linked hydrocephalus: evidence for closely related clinical entities of unknown molecular bases. Acta Neuropathol. 2013;126(3):427-442

21. Floridia M, Mastroiacovo P, Tamburrini E, et al; Italian Group on Surveillance on Antiretroviral Treatment in Pregnancy. Birth defects in a national cohort of pregnant women with HIV infection in Italy, 2001-2011. BJOG. 2013;120(12):1466-1475

22. Garcia-Flores J, Recio M, Uriel M, et al. Fetal magnetic resonance imaging and neurosonography in congenital neurologic anomalies: supplementary diagnostic and postnatal prognostic value. J Matern Fetal Neonatal Med. 2013;26(15):1517-1523

23. Hamisa M, Dabees N, Ataalla WM, et al. Magnetic resonance imaging versus ultrasound examination in detection of prenatal fetal brain anomalies. The Egyptian Journal of Radiology and Nuclear Medicine. 2013;44(3):665-672

24. Hergan B, Atar OD, Poretti A, Huisman TA. Serial fetal MRI for the diagnosis of Aicardi syndrome. Neuroradiol J. 2013;26(4):380-384

25. Huang $\mathrm{YH}$, Shu-Hang $\mathrm{N}$, Toh $\mathrm{C}-\mathrm{H}, \mathrm{Wu}$ $\mathrm{Y}-\mathrm{M}$, Wong $\mathrm{H}-\mathrm{F}$, Wong $\mathrm{AM}-\mathrm{C}$. Fetal ventriculomegaly: investigating additional brain abnormalities by using MR imaging. J Radiol Sci 2013;38:(2):35-41

26. Paladini D, Pastore G, Cavallaro A Massaro M, Nappi C. Agenesis of the fetal corpus callosum: sonographic signs change with advancing gestational age. Ultrasound Obstet Gynecol. 2013;42(6):687-690

27. Evangelidou P, Alexandrou A, Moutafi $\mathrm{M}$, et al. Implementation of high resolution whole genome array $\mathrm{CGH}$ in the prenatal clinical setting: 
advantages, challenges, and review of the literature. Biomed Res Int. 2013;2013:346762

28. Ganesamoorthy D, Bruno DL, McGillivray G, et al. Meeting the challenge of interpreting highresolution single nucleotide polymorphism array data in prenatal diagnosis: does increased diagnostic power outweigh the dilemma of rare variants?. BJOG. 2013;120(5):594-606

29. Hillman SC, McMullan DJ, Hall G, et al. Use of prental chromosomal microarray: prospective cohort study and systematic review and metaanalysis. Ultrasound Obstet Gynecol. 2013;41(6):610-620

30. Roorcyk C, Toutain J, Cailley D, et al. Prenatal diagnosis using array-CGH: a French experience. Eur J Med Genet. 2013;56(7):341-345

31. Schmid M, Stary S, Springer S, et al. Prenatal microarray analysis as second-tier diagnostic test: singlecenter prospective study. Ultrasound Obstet Gynecol. 2013;41(3): 267-273

32. Scott F, Murphy K, Carey L, et al. Prenatal diagnosis using combined quantitative flourescent polymerase chain reaction and array comparative genomic hybridization analysis as a first-line test: results from over 1000 consecutive cases. Ultrasound Obstet Gynecol. 2013;41(5):500-507

33. Srebniak MI, Mout L, Van Opstal D, Galjaard RJ. 0.5 Mb array as a firstline prenatal cytogenetic test in cases without ultrasound abnormalities and its implementation in clinical practice. Hum Mutat. 2013;34(9): 1298-1303

34. Dill P, Bosemani T, Bhakta M, Poretti A, Huisman TAGM. Impact of fetal magnetic resonance imaging on the management of fetal ventriculomegaly: Evaluation of 38 cases with an included synopsis. J Pediatr Neuroradiol. 2012;1(4):269-281

35. Kameda T, Yamada S, Uwabe C, Suganuma N. Digitization of clinical and epidemiological data from the Kyoto Collection of Human Embryos: maternal risk factors and embryonic malformations. Congenit Anom (Kyoto). 2012;52(1):48-54
36. Malinger G, Lev D, Oren M, LermanSagie T. Non-visualization of the cavum septi pellucidi is not synonymous with agenesis of the corpus callosum. Ultrasound Obstet Gynecol. 2012;40(2):165-170

37. Oh KY, Kennedy AM, Selden NR, McLean L, Sohaey R. Asymmetric ventriculomegaly, interhemispheric cyst, and dysgenesis of the corpus callosum (AVID): an imaging triad. J Ultrasound Med. 2012;31(11):1811-1820

38. Li Y, Estroff JA, Khwaja 0, et al. Callosal dysgenesis in fetuses with ventriculomegaly: levels of agreement between imaging modalities and postnatal outcome. Ultrasound Obstet Gynecol. 2012;40(5):522-529

39. Putoux A, Nampoothiri S, Laurent $\mathrm{N}$, et al. Novel KIF7 mutations extend the phenotypic spectrum of acrocallosal syndrome. J Med Genet. 2012;49(11):713-720

40. We JS, Young L, Park IY, et al. Usefulness of additional fetal magnetic resonance imaging in the prenatal diagnosis of congenital abnormalities. Arch Gynecol Obstet. 2012;286(6):1443-1452

41. Yamasaki M, Nonaka M, Bamba $Y$, Teramoto C, Ban C, Pooh RK. Diagnosis, treatment, and long-term outcomes of fetal hydrocephalus. Semin Fetal Neonatal Med. 2012;17 (6):330-335

42. Griffiths PD, Russell SA, Mason G, Morris J, Fanou E, Reeves MJ. The use of in utero MRI to delineate developmental brain abnormalities in multifetal pregnancies. AJNR Am J Neuroradiol. 2012;33(2):359-365

43. Armengol L, Nevado J, Serra-Juhé C, et al. Clinical utility of chromosomal microarray analysis in invasive prenatal diagnosis. Hum Genet. 2012;131(3):513-523

44. Breman A, Pursley AN, Hixson P, et al. Prenatal chromosomal microarray analysis in a diagnostic laboratory; experience with $>1000$ cases and review of the literature. Prenat Diagn. 2012;32(4):351-361

45. Bruno DL, Ganesamoorthy D, Schoumans J, et al. Detection of cryptic pathogenic copy number variations and constitutional loss of heterozygosity using high resolution SNP microarray analysis in 117 patients referred for cytogenetic analysis and impact on clinical practice. J Med Genet. 2009;46(2):123-131

46. Faas BH, Feenstra I, Eggink AJ, et al. Non-targeted whole genome 250K SNP array analysis as replacement for karyotyping in fetuses with structural ultrasound anomalies: evaluation of a one-year experience. Prenat Diagn. 2012;32(4):362-370

47. Filges I, Kang A, Klug V, et al. Array comparative genomic hybridization in prenatal diagnosis of first trimester pregnancies at high risk for chromosomal anomalies. Mol Cytogenet. 2012;5(1):38

48. Gruchy N, Decamp M, Richard N, et al. Array $\mathrm{CGH}$ analysis in high-risk pregnancies: comparing DNA from cultured cells and cell-free fetal DNA. Prenat Diagn. 2012;32(4):383-388

49. Hillman SC, McMullan DJ, Williams D, et al. Microarray comparative genomic hybridization in prenatal diagnosis: a review. Ultrasound Obstet. 2012;40(4):385-391

50. Novelli A, Grati FR, Ballarati L, et al. Microarray application in prenatal diagnosis: a position statement from the cytogenetics working group of the Italian Society of Human Genetics (SIGU), November 2011. Ultrasound Obstet Gynecol. 2012;39(4):384-388

51. Yatsenko SA, Davis S, Hendrix NW, et al. Application of chromosomal microarray in the evaluation of abnormal prenatal findings. Clin Genet. 2013;84(1):47-54

52. Shaffer LG, Rosenfeld JA, Dabell MP, et al. Detection rates of clinically significant genomic alterations by microarray analysis for specific anomalies detected by ultrasound. Prenat Diagn. 2012;32(10):986-995

53. Dhouib A, Blondiaux E, Moutard ML, et al. Correlation between preand postnatal cerebral magnetic resonance imaging. Ultrasound Obstet Gynecol. 2011;38(2):170-178

54. Haratz KK, Nardozza LM, de Oliveira PS, et al. Morphological evaluation of lateral ventricles of fetuses with ventriculomegaly by 
three-dimensional ultrasonography and magnetic resonance imaging: correlation with etiology. Arch Gynecol Obstet. 2011;284(2):331-336

55. Ozkan ZS, Gilgin H, Aygün HB, et al. Our clinical experience about prenatal diagnosis and neonatal outcomes of fetal central nervous system anomalies. J Matern Fetal Neonatal Med. 2011;24(3):502-505

56. Rouleau C, Gasner A, Bigi N, et al. Prevalence and timing of pregnancy termination for brain malformations. Arch Dis Child Fetal Neonatal Ed. 2011;96 (5):F360-F364

57. Rizzo G, Abuhamad AZ, Benacerraf $B R$, et al. Collaborative study on 3-dimensional sonography for the prenatal diagnosis of central nervous system defects. J Ultrasound Med. 2011;30(7):1003-1008

58. Fiorentino F, Caiazzo F, Napolitano S, et al. Introducing array comparative genomic hybridization into routine prenatal diagnosis practice: a prospective study on over 1000 consecutive clinical cases. Prenat Diagn. 2011;31(13):1270-1282

59. Leung TY, Vogel I, Lau TK, et al. Identification of submicroscopic chromosomal aberrations in fetuses with increased nuchal translucency and apparently normal karyotype. Ultrasound Obstet Gynecol. 2011;38(3):314-319

60. Park SJ, Jung EH, Ryu RS, et al. Clinical implementation of wholegenome array CGH as a first-tier test in 5080 pre and postnatal cases. Mol Cytogenet. 2011;9(4):12

61. Srebniak M, Boter M, Oudesluijs G, et al. Application of SNP array for rapid prenatal diagnosis: implementation, genetic counselling and diagnostic flow. Eur J Hum Genet. 2011;19(12):1230-1237

62. Di Bella D, Pizzo E. Non Vascular Congenital Brain Malformations. An MR Study of 5000 Patients. Neuroradiol J. 2010;23(3):284-291

63. Dommergues M, Mandelbrot L, Mahieu-Caputo D, Boudjema N, Durand-Zaleski I; ICI Group-Club de médecine foetale. Termination of pregnancy following prenatal diagnosis in France: how severe are the foetal anomalies? Prenat Diagn. 2010;30(6):531-539

64. Hosny IA, Elghawabi HS. Ultrafast MRI of the fetus: an increasingly important tool in prenatal diagnosis of congenital anomalies. Magn Reson Imaging. 2010;28(10):1431-1439

65. Peruzzi P, Corbitt RJ, Raffel C. Magnetic resonance imaging versus ultrasonography for the in utero evaluation of central nervous system anomalies. J Neurosurg Pediatr. 2010;6(4):340-345

66. Valduga M, Philippe C, Bach Segura $P$, et al. A retrospective study by oligonucleotide array-CGH analysis in 50 fetuses with multiple malformations. Prenat Diagn 2010;30(4):333-341

67. Winter TC, Kennedy AM, Byrne J, Woodward PJ. The cavum septi pellucidi: why is it important? J Ultrasound Med. 2010;29(3): 427-444

68. Manfredi R, Tognolini A, Bruno C, Raffaelli R, Franchi M, Pozzi Mucelli R. Agenesis of the corpus callosum in fetuses with mild ventriculomegaly: role of MR imaging. Radiol Med (Torino). 2010;115(2):301-312

69. Griffiths PD, Reeves MJ, Morris JE, et al. A prospective study of fetuses with isolated ventriculomegaly investigated by antenatal sonography and in utero MR imaging. AJNR Am J Neuroradiol. 2010;31(1):106-111

70. Warren DJ, Connolly DJ, Griffiths PD. Assessment of sulcation of the fetal brain in cases of isolated agenesis of the corpus callosum using in utero MR imaging. AJNR Am J Neuroradiol. 2010;31(6):1085-1090

71. Evangelidou P, Sismani C, Ioannides $M$, et al. Clinical application of wholegenome array CGH during prenatal diagnosis: study of 25 selected pregnancies with abnormal ultrasound findings or apparently balanced structural aberrations. Mol Cytogenet. 2010;3:24

72. Maya I, Davidov B, Gershovitz L, et al. Diagnostic utility of array-based comparative genomic hybridization (aCGH) in a prenatal setting. Prenat Diagn. 2010;30(12-13):1131-1137
73. Blaas HG, Eik-Nes SH. Sonoembryology and early prenatal diagnosis of neural anomalies. Prenat Diagn. 2009;29(4):312-325

74. Lerman-Sagie T, Ben-Sira L, Achiron $\mathrm{R}$, et al. Thick fetal corpus callosum: an ominous sign? Ultrasound Obstet Gynecol. 2009;34(1):55-61

75. Tang $\mathrm{PH}$, Ong $\mathrm{CL}$, Stringer $\mathrm{D}$, et al. Magnetic resonance imaging of the fetal central nervous system in Singapore. Ann Acad Med Singapore. 2009;38(9):774-781

76. Coppinger J, Alliman S, Lamb AN, et al. Whole-genome microarray analysis in prenatal specimens identifies clinically significant chromosome alterations without increase without increase in results of unclear significance compared to targeted microarray. Prenat Diagn. 2009;29(12):1156-1166

77. Kleeman L, Bianchi DW, Shaffer LG, et al. Use of array comparative genomic hybridization for prenatal diagnosis of fetuses with sonographic anomalies and normal metaphase karyotype. Prenat Diagn. 2009;29(13):1213-1217

78. Tyreman M, Abbott KM, Willatt LR, et al. High resolution array analysis: diagnosing pregnancies with abnormal ultrasound findings. J Med Genet. 2009;46(8):531-541

79. Van den Veyver IB, Patel A, Shaw CA, et al. Clinical use of array comparative genomic hybridization (aCGH) for prenatal diagnosis in 300 cases. Prenat Diagn. 2009;29(1):29-39

80. Vialard F, Molina Gomes D, Leroy B. Array comparative genomic hybridization in prenatal diagnosis: another experience. Fetal Diagn Ther. 2009;25 (2):277-284

81. Callen PW, Callen AL, Glenn OA, Toi A. Columns of the fornix, not to be mistaken for the cavum septi pellucidi on prenatal sonography. J Ultrasound Med. 2008;27(1):25-31

82. Hagmann CF, Robertson $\mathrm{NJ}$, Leung WC, et al. Foetal brain imaging: ultrasound or MRI. A comparison between magnetic resonance imaging and a dedicated multidisciplinary neurosonographic opinion. Acta Paediatr. 2008;97 (4):414-419 
83. Hadzagić-Catibusić F, Maksić $\mathrm{H}$, Uzicanin S, et al. Congenital malformations of the central nervous system: clinical approach. Bosn J Basic Med Sci. 2008;8(4):356-360

84. Bi W, Breman AM, Venable SF, et al. Rapid prenatal diagnosis using uncultured amniocytes and oligonucleotide array CGH. Prenat Diagn. 2008;28(10):943-949

85. Benacerraf BR, Shipp TD, Bromley $B$, et al. What does magnetic resonance imaging add to the prenatal sonographic diagnosis of ventriculomegaly? J Ultrasound Med. 2007;26(11):1513-1522

86. Breeze AC, Dey PK, Lees CC, Hackett GA, Smith GC, Murdoch EM. Obstetric and neonatal outcomes in apparently isolated mild fetal ventriculomegaly. J Perinat Med. 2005;33(3):236-240

87. Moritake K, Nagai H, Miyazaki T, Nagasako N, Yamasaki M, Tamakoshi A. Nationwide survey of the etiology and associated conditions of prenatally and postnatally diagnosed congenital hydrocephalus in Japan. Neurol Med Chir (Tokyo). 2007;47 (10):448-452, discussion 452

88. Sohn YS, Kim MJ, Kwon JY, Kim YH, Park YW. The usefulness of fetal MRI for prenatal diagnosis. Yonsei Med J. 2007;48(4):671-677

89. De Gregori M, Ciccone R, Magini P, et al. Cryptic deletions are a common finding in "balanced" reciprocal and complex chromosome rearrangements: a study of 59 patients. J Med Genet. 2007;44(12):750-762

90. Gullotta F, Biancolella M, Costa E, et al. Prenatal diagnosis of genomic disorders and chromosome abnormalities using array-based comparative genomic hybridization. J Prenat Med. 2007;1(1):16-22

91. Lee CS, Hong SH, Wang KC, et al. Fetal ventriculomegaly: prognosis in cases in which prenatal neurosurgical consultation was sought. J Neurosurg. 2006;105 (4 Suppl):265-270

92. Sacco S, Moutard ML, Fagard J. Agenesis of the corpus callosum and the establishment of handedness. Dev Psychobiol. 2006;48(6): 472-481
93. Rickard S, Morris J, Paley M, Griffiths P, Whitby E. In utero magnetic resonance of non-isolated ventriculomegaly: Does ventricular size or morphology reflect pathology? Clin Radiol. 2006;61(10):844-853

94. Miura S, Miura K, Masuzaki H, et al. Microarray comparative genomic hybridization (CGH)-based prenatal diagnosis for chromosome abnormalities using cell-free fetal DNA in amniotic fluid. J Hum Genet. 2006;51(5):412-417

95. Sahoo T, Cheung SW, Ward P, et al. Prenatal diagnosis of chromomal abnormalities using array-based comparative genomic hybridization. Genet Med. 2006;8(11):719-727

96. Belhocine 0, André C, Kalifa G, Adamsbaum C. Does asymptomatic septal agenesis exist? A review of 34 cases. Pediatr Radiol. 2005;35(4):410-418

97. Blaicher W, Prayer D, Mittermayer C, et al. The clinical impact of magnetic resonance imaging in fetuses with central nervous system anomalies on ultrasound scan. Ultraschall Med. 2005;26(1):29-35

98. Breeze AC, Alexander PM, Murdoch EM, Missfelder-Lobos HH, Hackett GA, Lees CC. Obstetric and neonatal outcomes in severe fetal ventriculomegaly. Prenat Diagn. 2007;27(2):124-129

99. Brown WS, Paul LK, Symington $M$, Dietrich R. Comprehension of humor in primary agenesis of the corpus callosum. Neuropsychologia. 2005;43(6):906-916

100. Leung KY, Ngai CS, Chan BC, Leung WC, Lee CP, Tang MH. Three-dimensional extended imaging: a new display modality for three-dimensional ultrasound examination. Ultrasound Obstet Gynecol. 2005;26(3):244-251

101. D’Addario V, Pinto V, Di Cagno L, Pintucci A. The midsagittal view of the fetal brain: a useful landmark in recognizing the cause of fetal cerebral ventriculomegaly. J Perinat Med. 2005;33(5):423-427

102. La Caignec C, Boceno M, SaugierVeber $P$, et al. Detection of genomic imbalances by array based comparative genomic hybridisation in fetuses with multiple malformations. J Med Genet. 2005;42 (2):121-128

103. Rickman L, Fieger H, Shaw-Smith C, et al. Prenatal detection of unbalanced chromosomal rearrangements by array CGH. J Med Genet. 2006;43(4):353-361

104. Frates MC, Kumar AJ, Benson CB, Ward VL, Tempany CM. Fetal anomalies: comparison of MR imaging and US for diagnosis. Radiology. 2004;232 (2):398-404

105. Guillem P, Fabre B, Cans C, RobertGnansia E, Jouk PS. Trends in elective terminations of pregnancy between 1989 and 2000 in a French county (the Isère). Prenat Diagn. 2003;23(11):877-883

106. Malinger G, Ben-Sira L, Lev D, et al. Fetal brain imaging: a comparison between magnetic resonance imaging and dedicated neurosonography. Ultrasound Obstet Gynecol. 2004;23(4):333-340

107. Whitby EH, Paley MN, Sprigg A, et al. Comparison of ultrasound and magnetic resonance imaging in 100 singleton pregnancies with suspected brain abnormalities. BJOG. 2004;111(8):784-792

108. Wald M, Lawrenz K, Deutinger J, Weninger M. Verification of anomalies of the central nervous system detected by prenatal ultrasound. Ultraschall Med. 2004;25(3):214-217

109. Larrabee PB, Johnson KL, Pestova E, et al. Microarray analysis of cell-free fetal DNA in amniotic fluid: a prenatal molecular karyotype. Am J Hum Genet. 2004;75(3):485-491

110. Twickler DM, Magee KP, Caire J, et al Second-opinion magnetic resonance imaging for suspected fetal central nervous system abnormalities. Am J Obstet Gynecol. 2003;188(2):492-496

111. Bekker MN, van Vugt JM. The role of magnetic resonance imaging in prenatal diagnosis of fetal anomalies. Eur J Obstet Gynecol Reprod Biol. 2001;96(2):173-178

112. Whitby E, Paley MN, Davies N, et al. Ultrafast magnetic resonance imaging of central nervous system abnormalities in utero in the second and third trimester of pregnancy: 
comparison with ultrasound. BJOG. 2001;108(5):519-526

113. Greco P, Vimercati A, De Cosmo L, et al. Mild ventriculomegaly as a counselling challenge. Fetal Diagn Ther. 2001;16(6):398-401
114. Ickowitz V, Eurin D, Rypens F, et al. Prenatal diagnosis and postnatal follow-up of pericallosal lipoma: report of seven new cases.

AJNR Am J Neuroradiol. 2001;22(4): 767-772
115. Marszał E, Jamroz E, Pilch J, Kluczewska E, Jabłecka-Deja $\mathrm{H}$, Krawczyk R. Agenesis of corpus callosum: clinical description and etyology. J Child Neurol. 2000;15(6):401-405 